Article

\title{
Energy Efficient, Highly Precise Cascade Dryness Control for Fibrous Tape by Induction-Based Surface Heating of a Rotating Steel Cylinder with Moving Inductors
}

\author{
Jacek Kucharski, Andrzej Fraczyk and Piotr Urbanek*
}

Citation: Kucharski, J.; Fraczyk, A.; Urbanek, P. Energy Efficient, Highly Precise Cascade Dryness Control for Fibrous Tape by Induction-Based Surface Heating of a Rotating Steel Cylinder with Moving Inductors. Appl. Sci. 2022, 12, 261. https:// doi.org/10.3390/app12010261

Academic Editor: Radu Godina

Received: 6 December 2021

Accepted: 23 December 2021

Published: 28 December 2021

Publisher's Note: MDPI stays neutral with regard to jurisdictional claims in published maps and institutional affiliations.

Copyright: (C) 2021 by the authors. Licensee MDPI, Basel, Switzerland. This article is an open access article distributed under the terms and conditions of the Creative Commons Attribution (CC BY) license (https:// creativecommons.org/licenses/by/ $4.0 /)$.
Institute of Applied Computer Science, Lodz University of Technology, 90-537 Lodz, Poland; jacek.kucharski@p.lodz.pl (J.K.); andrzej.fraczyk@p.lodz.pl (A.F.)

* Correspondence: piotr.urbanek@p.lodz.pl

\begin{abstract}
Drying various materials constitutes an essential component of several industrial processes, e.g., paper production. Typically, rotating cylinders heated internally by water steam are used for drying tape-shaped material in paper-making machines. Such an approach remains very energyconsuming, while the whole process is expensive and in conflict with the global policy of reducing energy consumption in heavy industry. One promising alternative method of drying fibrous tapes is the induction heating of drying cylinders. In this paper, we propose a drying system based on a set of inductors (electromagnetic field sources) that generate energy in the mantle of the cylinder and dry the running tape. By enabling the movement of the inductors, the system provides a high level of flexibility in terms of reacting to the varying humidity of the tape. Additionally, imaging the temperature field on the cylinder surface provides a supplementary source of information, enabling the temperature profile to be controlled. Two types of humidity control systems, a one-loop feedback control and a cascade control, were designed and analyzed. Simulation analysis and experimental verification performed using a semi-industrial setup proves that using the proposed cascade control ensures more than $30 \%$ faster response of the whole dryness control system.
\end{abstract}

Keywords: dryness control algorithms; induction heating; thermal imaging; cascade control algorithm

\section{Introduction}

Processes for drying materials of various structures (solid, powdery, or fibrous) to the required humidity are often very energy- and time-consuming. This makes them very expensive and in conflict with the global policy of reducing energy consumption in heavy industry. These practical observations have been confirmed by mathematical descriptions of the process of drying porous materials [1]. In the case of drying hygroscopic materials (e.g., in paper webs), the process mainly involves ensuring the required (usually uniform) distribution of humidity over the entire width of the material [2], which is difficult to achieve in practice. Improving the existing drying methods has therefore become the focus of intense research. For example, in [3], the authors studied the possibility of controlling paper humidity by changing the pressure of the steam that heats the cylinder in papermaking machines. Other works [4] have focused on installing special steam boxes, which can balance the moisture in the paper web using dedicated steam nozzles. The drying process is then carried out in the standard way, by the internal heating of the drying cylinders using water steam. Although both of these solutions have positive effects on drying, they are still very energy consuming.

A promising alternative method of drying fibrous tapes is by the induction heating of the drying cylinders. Because this approach uses electricity as a power source, it is very effective and ecological. However, most research so far has consisted of theoretical works involving the creation of mathematical and numerical models of the induction heating process and of phenomena occurring on the surface of the drying cylinder [5-10]. Moreover, 
new designs of inductors which generate the dominant component of the electromagnetic field transverse to the charge plane are able to heat moving objects much larger than the inductors themselves, including rotating drying cylinders. This type of inductor is particularly well suited to automatic power control, whereby thermal energy can be flexibly generated in various areas of the drying cylinder, depending on the different levels of humidity in the tape [11]. Since, in drying devices based on drying rollers, the change in humidity is strongly related to changes to the temperature on the surface of the drying roller [12], it can be assumed that by controlling the temperature profile of the drying roller it will be possible to shape the dryness profile of the tape. The temperature profile can be monitored using, for example, a set of thermocouple elements [13,14]. However, work on temperature control is currently focused on monitoring not only temperature profiles but also their two-dimensional distributions [15-18], notably using thermal imaging cameras [19-22]. To control the temperature profile, it is possible to use both classic control methods [23-25], methods based on artificial intelligence, e.g., Fuzzy Logic [26] or Neural Networks [27], and methods dedicated to specific applications [28,29]. The classical PIDtype method of control is used to control dryness [30].

In this paper, a holistic approach to the issue of drying fibrous tape is proposed, consisting of a numerical analysis of the induction heating of a drying cylinder, temperature profile control at the cylinder surface, and an automated drying process. The numerical analysis was based on Finite Element Method (FEM) which was implemented in commercial software under the name Flux 2D/3D made by Cedrat Corp. France. Those simulations covered the coupled electromagnetic and thermal calculations, taking into account the non-linear material properties of the calculation areas. Based on those calculations, the dynamics characteristic of heating a rotating cylinder and the appropriate transmittance models of study system were determined.

The proposed method of modeling dryness control uses the surface temperature of the cylinder as an auxiliary signal. This is more effective than classic control methods because it allows for faster humidity control. The results of the numerical analysis were confirmed by a series of experiments on a real semi-industrial system.

The paper is organized as follows. In Section 2, a practical implementation of the developed method, in the form of a semi-industrial laboratory system for drying cotton tape using six independently supplied and controlled movable inductors is presented. A numerical model of the process of induction heating of a rotating cylinder, along with an analysis of the heating conditions, is described in Section 3. In Section 4, we analyze the temperature distribution at the cylinder surface and propose two algorithms for controlling the position and power of the inductors. In Section 5, we analyze the process of drying cotton tape using a single PI control loop structure and a cascade control with an auxiliary signal for surface temperature. The results are verified experimentally.

\section{Experimental, Semi-Industrial Setup}

The idea of the experimental system for wet fiber tape drying is presented in Figure 1. Selected views of its practical realization are shown in Figure 2. Within the system of guides ensuring transport and moistening of the web, four main functional subsystems can be distinguished: an induction-heated rotating steel cylinder with HF generators, a tape dryness measurement system, a surface temperature imaging system and a temperature and a dryness control system. The control system is fed by both measurement subsystems, yielding an output signal for the HF generators such that both a single dryness control loop and cascade control can be achieved. 


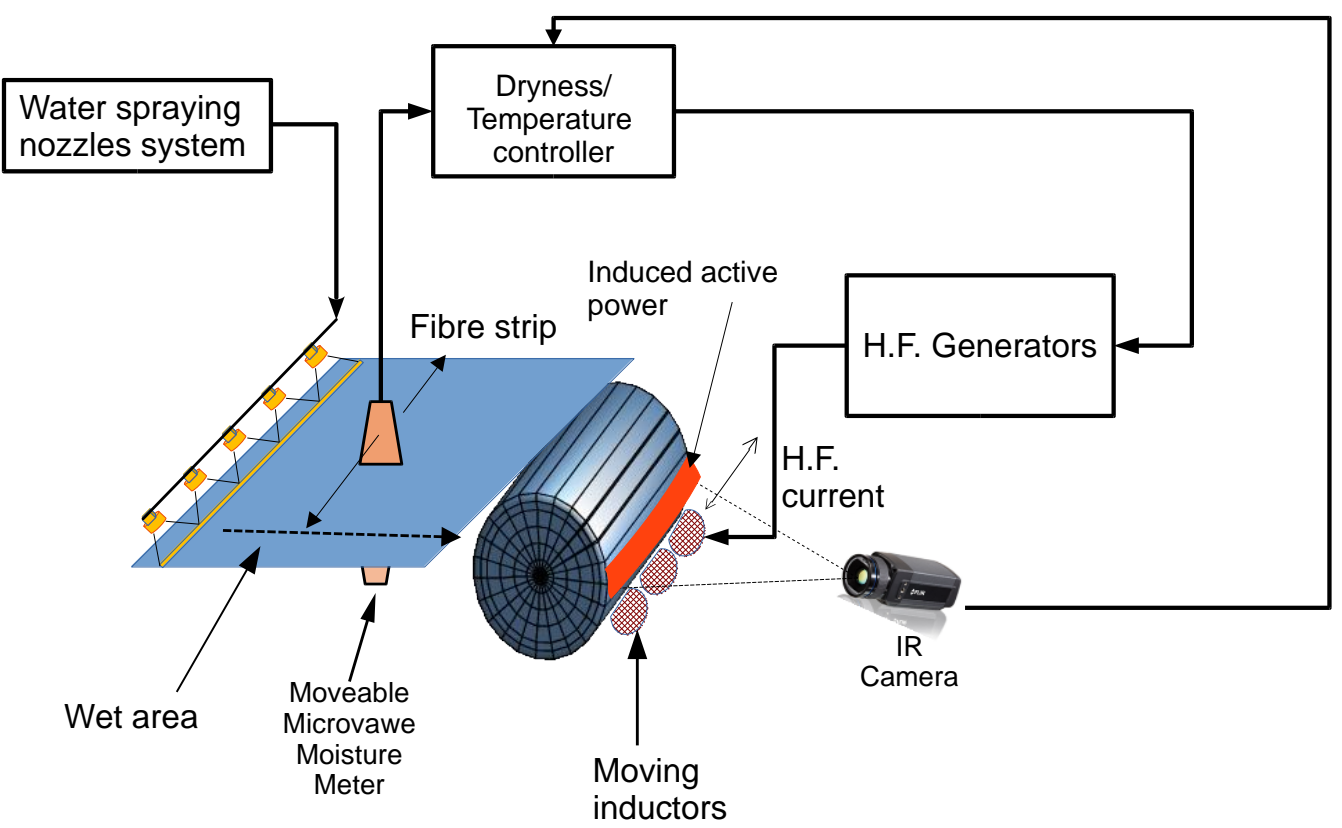

Figure 1. Schematic diagram of the system for the automatic drying of wet fiber tape.

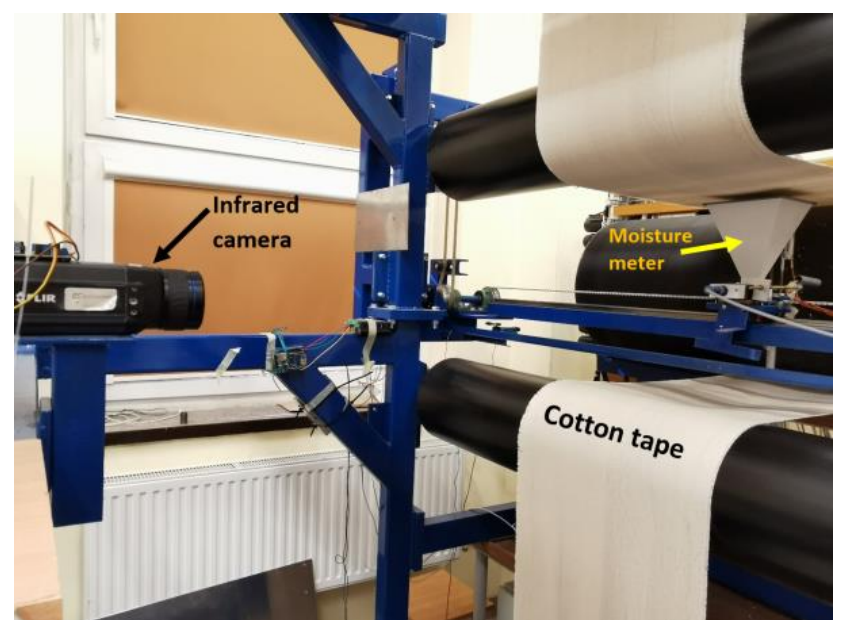

(a)

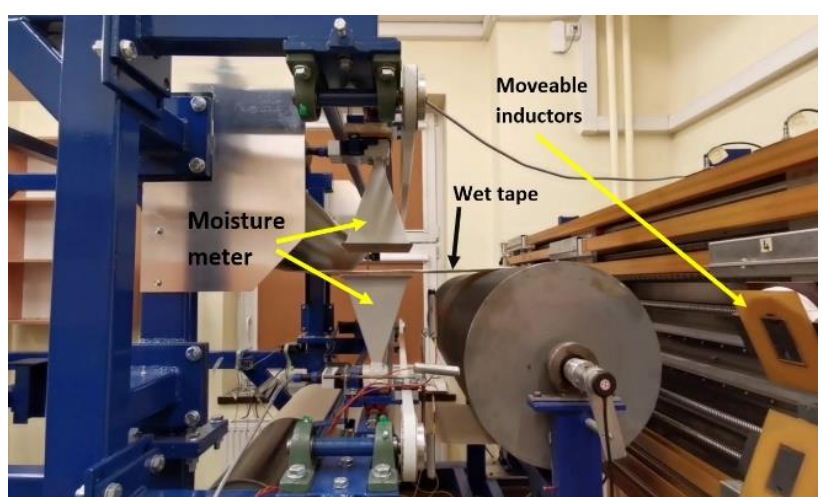

(b)

Figure 2. General view of the actual drying stand (a). Side view of the dryness meter and moving inductors heating the cylinder (b).

The most crucial parts of the setup are shown in Figure 3. The induction heating system constitutes the main part. As discussed in Section 3, to ensure flexibility in forming the surface temperature distribution, the inductors have to be able to generate heating power in any area of the cylinder. Therefore, the inductors must be capable of independent movement above and along the axis of the cylinder surface. The inductors (2) are mounted on individual carriages (3) arranged in two sections, ensuring symmetry with respect to the generatrix of the cylinder axis (4). The trolleys are mechanically connected to each other by means of guides (5), which stabilize their movement along the cylinder length using a pull ball screw (7). The screws are driven individually by servos (6). A schema of the subsystem is shown in Figure 3. 


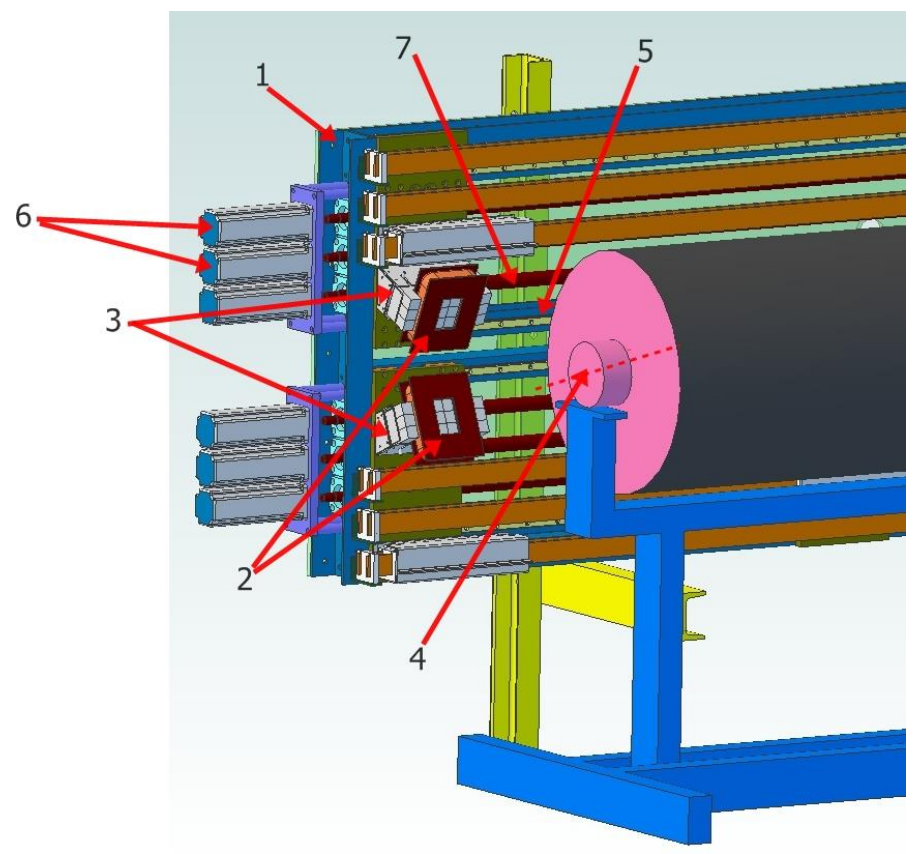

Figure 3. Schema of the motive system of the inductors along the axis of the cylinder.

Since, under real working conditions, the inductors can be in permanent movement for long periods of time, a robust power supply is needed. For this purpose, a dedicated wireless power supply system was developed, as shown in Figure 4. This solution uses an intermediate transformer (IT) with a stretched primary winding (PWS), connected to an inverter (INV) giving a current of $20 \mathrm{kHz}$ frequency. The winding, which is arranged along the forming cylinder, is fixed, while the transformer core (IT), which is mechanically and electrically connected to the inductor, moves on a specially constructed trolley (SP). In any position of the transformer core, electricity is transferred through the IT transformer from the inverter to the inductor.

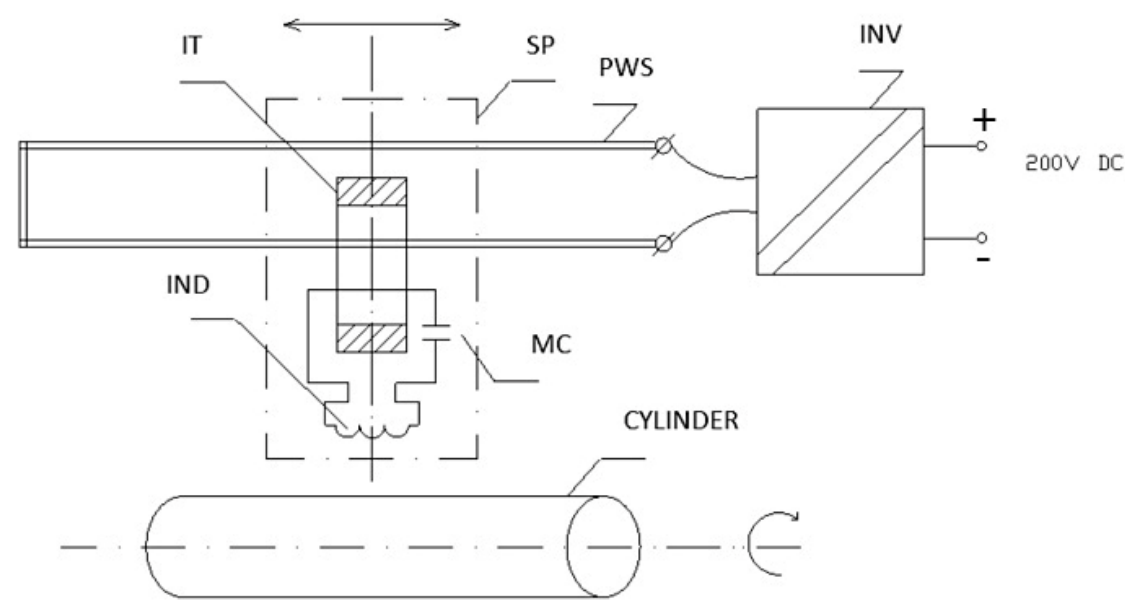

Figure 4. Electrical diagram of the wireless power supply for moving the inductors. IT-transformer core; SP—specially constructed trolley; PWS—-primary winding; INV—hf inverter; IND—inductor; $\mathrm{MC}$ - matching condenser.

The measuring sub-system is equipped with a microwave moisture meter and a thermal imaging camera. The moisture meter consists of two antennas, one of which (the emitter) emits microwave radiation that is partially absorbed by water molecules contained in the fibrous tape. The second antenna (the receiver) receives the unabsorbed part of the signal, thus measuring the humidity (or degree of dryness) of the tape. Both antennas are 
movable, so the humidity of the entire tape can be scanned systematically. An infrared camera (A615 by Flir) is used to measure the temperature distribution over the visible part of the cylinder surface, based on which the temperature distribution along the generatrix of the cylinder is determined. An measurement example is shown in Figure $5 \mathrm{a}, \mathrm{b}$.

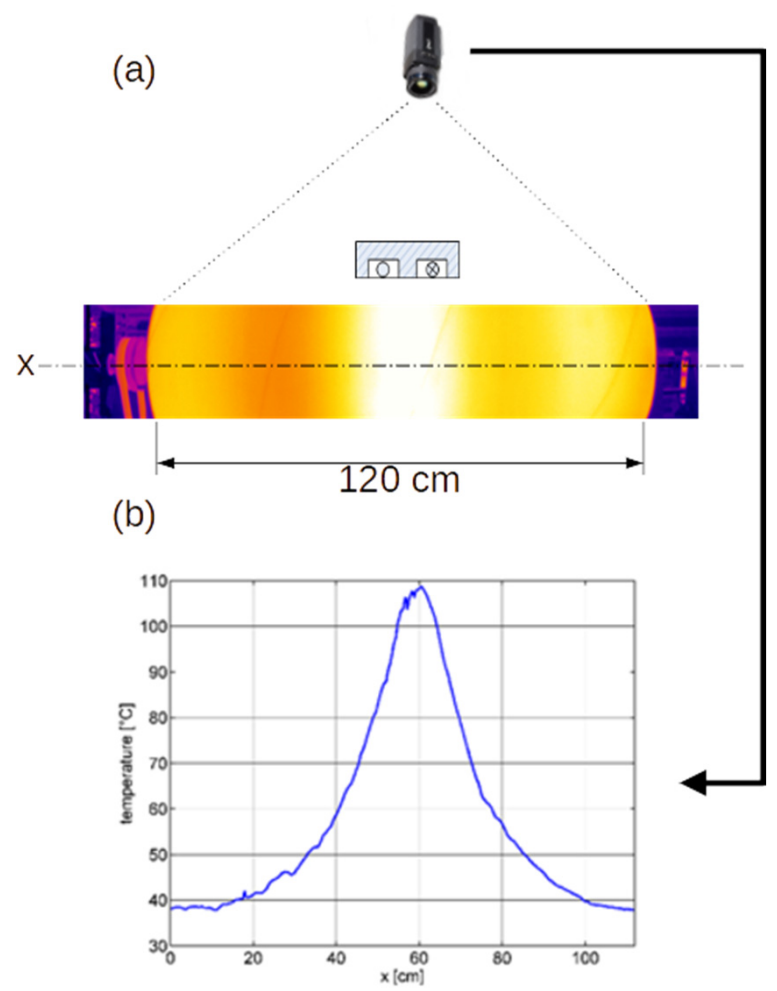

Figure 5. Example of measuring the surface temperature of a rotating cylinder using a thermal imaging camera. (a) Two-dimensional temperature map of the surface of the rotating cylinder processed by an IR camera. (b) One-dimensional temperature distribution along the generatrix of cylinder $\mathrm{x}$.

\section{Numerical Model of Induction Heating a Rotating Steel Cylinder}

Designing an efficient drying system, in which a wet tape surrounding a rotating drying cylinder is heated by a high-frequency electromagnetic field, requires careful analysis of various phenomena. First, the mechanism of energy exchange between the electromagnetic field source, the inductor, and the cylinder mantle has to be modelled. The resulting model of the thermal field directly influencing the drying tape should then be determined. Several characteristic features of the induction heated drying setup have to be taken into consideration, including the specificity of the electromagnetic field resulting from the type of inductor and its spatial location against the cylinder, the rotating movement of the cylinder, and the mutual dependence of the electromagnetic and thermal fields [31-33]. All these phenomena can be described analytically by well-known mathematical formalities [34], but a fully functional model of the proposed drying system can be developed only by computer simulations [8,35-37]. An illustrative diagram of our numerical model of an induction-heated steel roller is shown in Figure 6. 


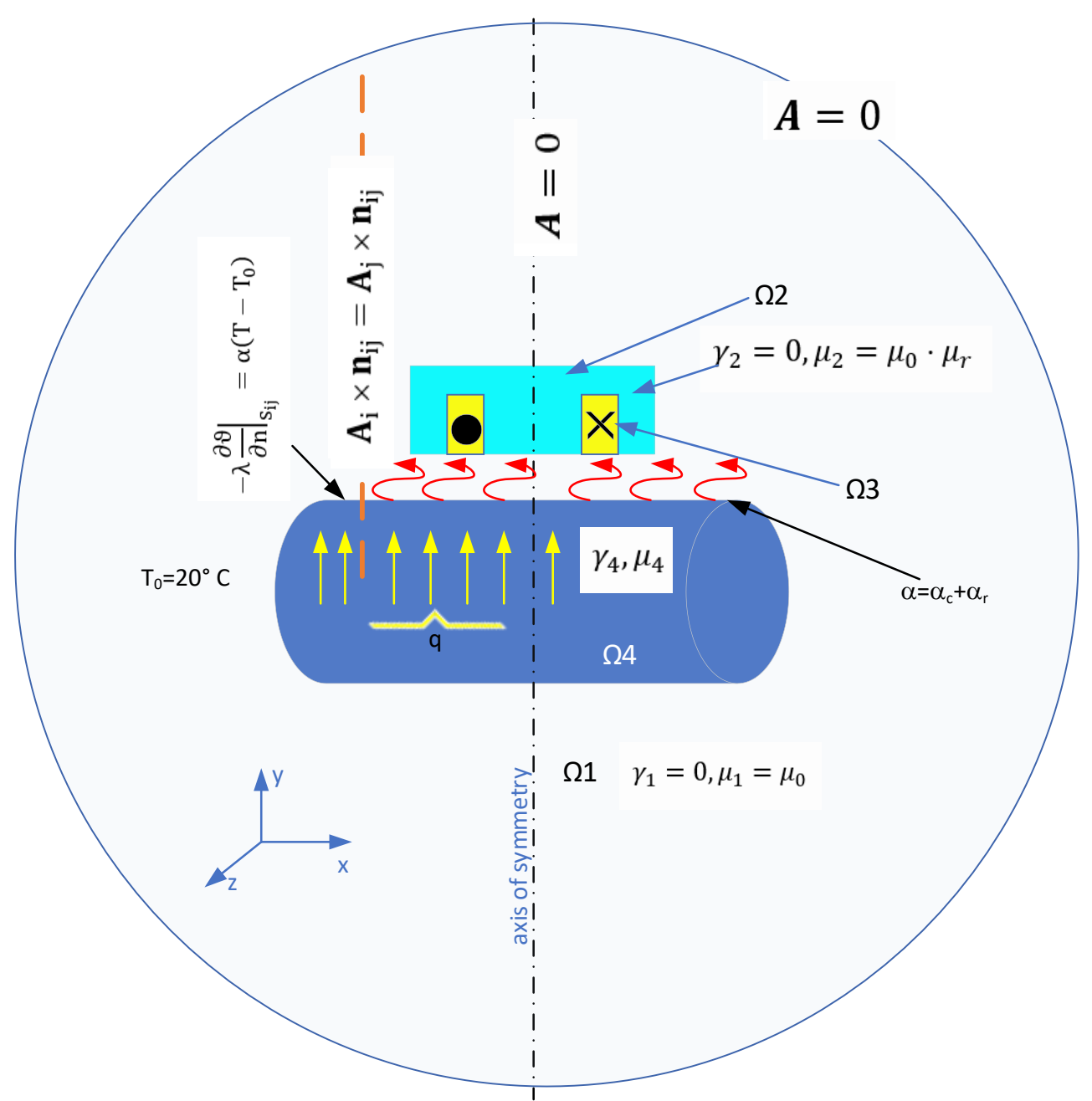

Figure 6. Areas modeled in the inductor-steel cylinder system with boundary conditions for the electromagnetic field. The figure is not to scale. $\Omega 1$-area of the air gap and the environment of the heating system; $\Omega 2$ - area of the ferromagnetic core; $\Omega 3$-winding area; $\Omega 4$-area of the cylinder, $\gamma$-electric conductivity of the $\Omega 4$ area; $\omega$-pulsation of the electromagnetic field, $\varepsilon_{0}$-vacuum permittivity; $\varepsilon_{\mathrm{r}}$-relative permittivity; $\mu_{0}$-magnetic permeability of free space; $\mu_{\mathrm{r}}$-relative magnetic permeability, $\alpha$-heat transfer coefficient, $\alpha_{r}$-radiation heat transfer, $\alpha_{c}$ - convection heat transfer, $\lambda$-conduction, $\mathrm{T}$-temperature.

In the modeled system, the following simplifying assumptions were made:

- $\quad$ The anisotropy of the material properties of the cylinder area $\Omega 4$ was omitted. It was assumed that during calculation of the power P generated in the cylinder the cylinder does not move.

- In the winding area $\Omega 3$, a harmonic current of 17A flows in the entire volume of the winding (this is the so-called Litz wire). In this area, no active power is released.

- Zero conductivity of the ferromagnetic core $\Omega 2$ is assumed, and the anisotropy of the material properties of this area is omitted.

- For the area of the air gap and the environment of the heating system $\Omega 1$, a compromise is assumed between the size of the division into finite elements and the accuracy of the disappearance of the magnetic field at the edge of the area.

- In the induction heated rotating steel cylinder, the conduction current is much greater than the displacement current-i.e., $\gamma \gg \omega \varepsilon_{0} \varepsilon_{\mathrm{r}}$.

- The induction of eddy currents in the cylinder due to its rotational speed is omitted.

With the above assumptions, the combined magnetic vector potential for the separated areas of the inductor-cylinder system takes the following forms: 
- $\quad$ For the cylinder area $\Omega 4$ :

$$
\nabla^{2} \underline{\mathbf{A}}-j \omega \mu \gamma \underline{\mathbf{A}}=0
$$

- $\quad$ For magnetic shunt areas $\Omega 2$ and free space $\Omega 1$ :

$$
\nabla^{2} \underline{\mathbf{A}}=0
$$

- For the inductor area $\Omega 3$ :

$$
\nabla^{2} \underline{\mathbf{A}}-j \omega \mu \gamma \underline{\mathbf{A}}=-\mu \mathrm{J}_{\mathrm{w}}
$$

where Jw-the forced current density in the inductor winding; $\omega=2 \pi \mathrm{f}-$ supply current pulsation (f-frequency); $\mu=\mu_{0} \mu_{\mathrm{r}}$-magnetic permeability of the medium ( $\mu_{0}=4 \mu \cdot 10^{-7} \mathrm{H} / \mathrm{m}, \mu_{\mathrm{r}}$-relative magnetic permeability of the medium); $\gamma$-conductivity of the medium; $\mathrm{J}_{\mathrm{W}}$-force current.

Using the magnetic vector potential $A$, the volumetric power density $p_{v}$ in the charge can be calculated according to the following formula:

$$
\mathrm{p}_{\mathrm{v}}=\gamma \omega^{2} \underline{\mathbf{A} \cdot \mathbf{A}^{*}}
$$

where $\mathbf{A}^{*}$ is the conjugate number of the vector potential $\mathbf{A}$.

To obtain an unambiguous solution of the power density distribution on the cylinder surface, boundary conditions should be formulated at the edge of the calculation area $\Omega 1$, where by assumption the magnetic field disappears. Therefore,

$$
\mathbf{A}=0
$$

Condition (5) can also be applied to the plane of symmetry of the modelled system, since the currents in the inductor coil have the opposite conducting direction (the magnetic field force lines eliminate each other). In addition, at the intersection of the areas of the cylinder $\Omega 4$ (a conductive area), air $\Omega 1$ (a non-conductive area), and the core of the inductor $\Omega 1$ (the non-conductive area of the ferromagnets), the normal components of magnetic induction are equal, which gives the following boundary condition for the vector potential:

$$
\mathbf{A}_{\mathrm{i}} \times \mathbf{n}_{\mathrm{ij}}=\mathbf{A}_{\mathbf{j}} \times \mathbf{n}_{\mathrm{ij}}
$$

where $i$ and $j$ are area indicators $\Omega_{i}$, and $n_{i j}$ is the normal vector for the contact area surfaces $\Omega_{\mathrm{i}}$ and $\Omega_{\mathrm{j}}$.

The temperature field of the cylinder area $(\Omega 4)$ in the analyzed system is described by the Fourier-Kirchhoff law:

$$
\nabla^{2} \vartheta-\frac{\mathrm{c} \rho}{\lambda} \cdot \frac{\partial \vartheta}{\partial \mathrm{t}}=-\frac{\mathrm{p}_{\mathrm{v}}}{\lambda}
$$

where: T—cylinder area temperature $\left({ }^{\circ} \mathrm{C}\right) ; \mathrm{c}$ - specific heat of the cylinder material $(\mathrm{J} / \mathrm{kgK})$; $\rho$-resistivity of the cylinder material $(\Omega) ; \lambda$-specific thermal conductivity of the cylinder material (W/mK); and t-time (s).

The unambiguous solution of temperature field distribution is ensured by the Neuman condition at the area between the surface of the cylinder $\Omega 4$ and the environment $\Omega 1$ :

$$
-\left.\lambda \frac{\partial \vartheta}{\partial \mathrm{n}}\right|_{S_{\mathrm{ij}}}=\alpha\left(\mathrm{T}-\mathrm{T}_{0}\right)
$$

where: $\mathrm{T}_{0}$-ambient temperature; $\alpha=\alpha_{\text {conv }}+\alpha_{\text {rad }}$-the total heat transfer coefficient with the environment consisting of convection $\left(\alpha_{\text {conv }}\right)$ and radiation $\left(\alpha_{\text {rad }}\right)$ heat transfer.

On the edges of the $\Omega 1$ area, the following initial condition was assumed:

$$
\mathrm{T}(\mathrm{x}, \mathrm{y}, \mathrm{z}, \mathrm{t}=0)=\mathrm{T}_{0}=20^{\circ} \mathrm{C}
$$

The physical properties of modelled areas are given in Table 1: 
Table 1. Physical properties of modelled areas.

\begin{tabular}{|c|c|c|c|c|}
\hline $\begin{array}{c}\text { Symbol of } \\
\text { Calculations Area }\end{array}$ & $\mu_{\mathrm{r}}(-)$ & $\gamma(\mathrm{S})$ & $\lambda(\mathrm{W} / \mathrm{m} \mathrm{K})$ & $\rho c\left(J / m^{3} K\right)$ \\
\hline$\Omega 1$ & 1 & 0 & - & - \\
\hline$\Omega 2$ & 1000 & 0 & - & - \\
\hline$\Omega 3$ & 1 & $\propto$ & - & - \\
\hline$\Omega 4$ & $\begin{array}{l}\text { According to } \mathrm{B}=\mathrm{f}(\mathrm{H}) \text { charcteristics } \\
\text { built in Flux software database } \\
\text { (FLU_STEEL_1010_XC10) by Cedrat }\end{array}$ & $2.94 \times 10^{6}$ & 47 & $4.5 \times 10^{6}$ \\
\hline
\end{tabular}

The total heat transfer coefficient between cylinder surface and environment is determined as nonlinear equation: $200\left(\mathrm{~W} / \mathrm{m}^{2} \mathrm{~K}\right)$, emissivity as 0.8 .

Another crucial aspect of the modelling method is the inclusion of the rotation of the heated cylinder. This movement was imitated by the superposition of 36 positions of rotation (every $10^{\circ}$ ). Full calculation domain with meshing is presented in Figure 7 . The flowchart of these calculations is shown in Figure 8.

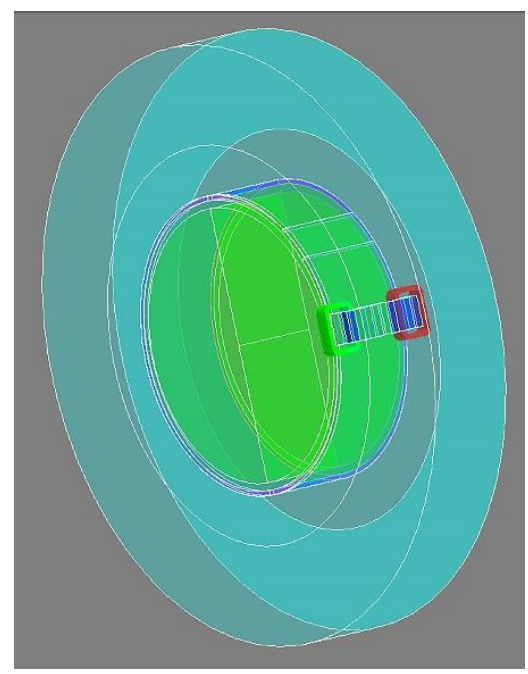

(a)

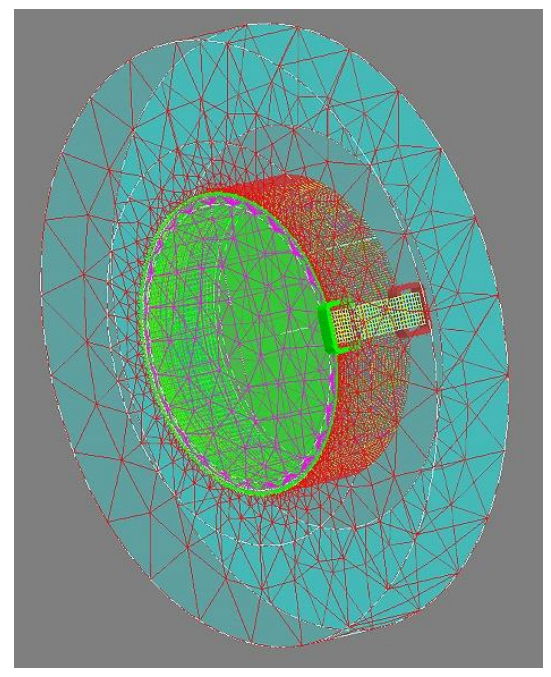

(b)

Figure 7. The calculation domain of the inductors-rotating cylinder system: volume regions (a), meshing of volume regions (b).

The meshing of volume elements was checked automaticaly, resulting in $54.95 \%$ nonevaluated elements, $22.4 \%$ excellent quality elements, $16.58 \%$ good quality elements, $5.34 \%$ average quality elements, and only $0.74 \%$ poor quality elements.

In the initial step of the simulation, for time $\mathrm{T}=0$ and angle $\alpha=0$, the distribution of the electromagnetic field in the inductor-cylinder system and the distribution of the active power induced in the cylinder mantle are calculated. These calculations take into account the nonlinear dependence of the magnetic induction $\mathbf{B}$ on the electromagnetic field intensity $\mathbf{H}$ (changing the $\mu_{\mathrm{r}}$ value). This requires multiple iterations of calculations of the induction distribution, $B$, and of the volumetric active power $p_{v}$ (block [1] in Figure 8), until the convergence conditions are fulfilled. Examples of the results are shown in Figure 9a,b. 


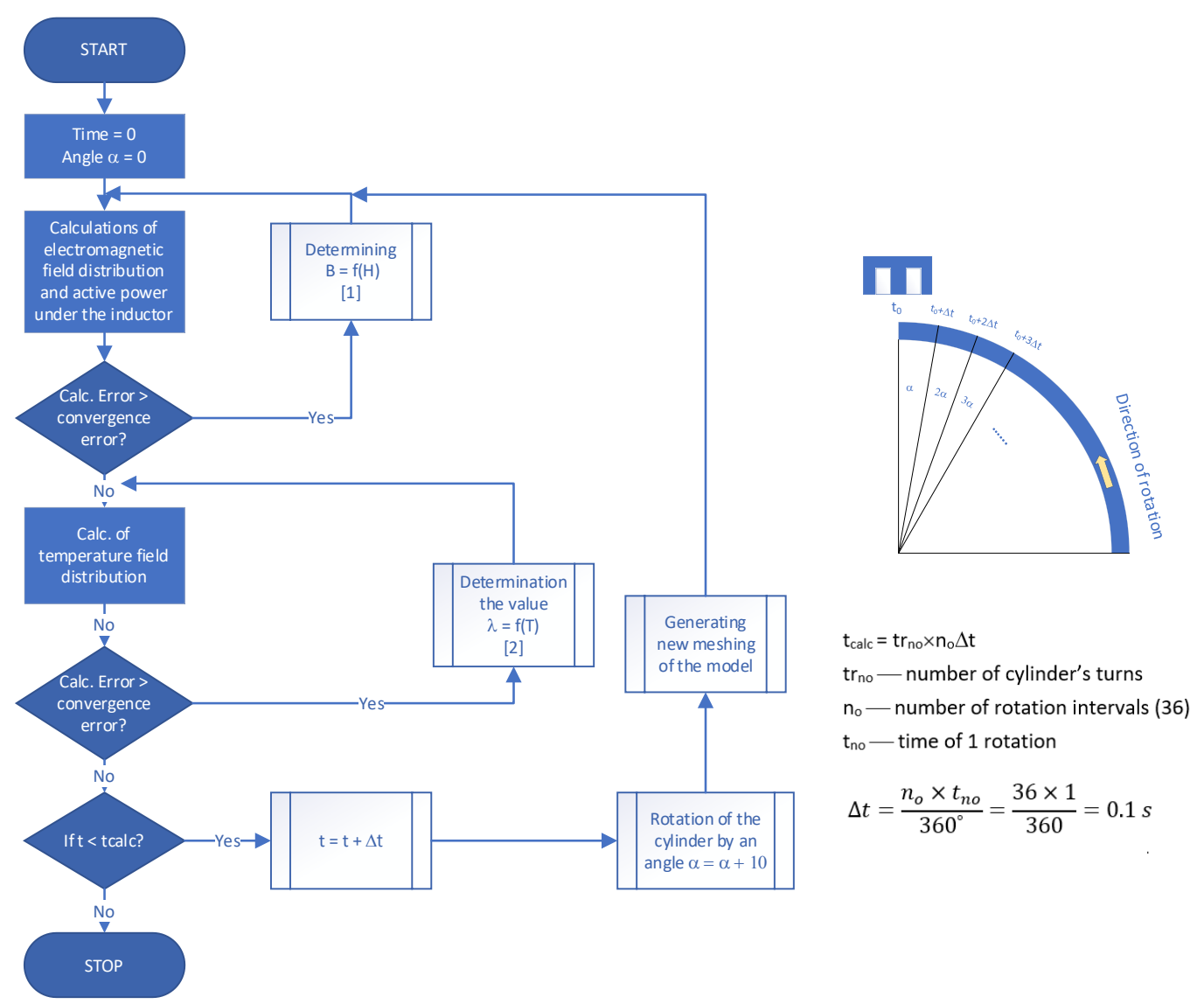

Figure 8. Flowchart of the process of calculating the induction heating of a rotating steel cylinder.

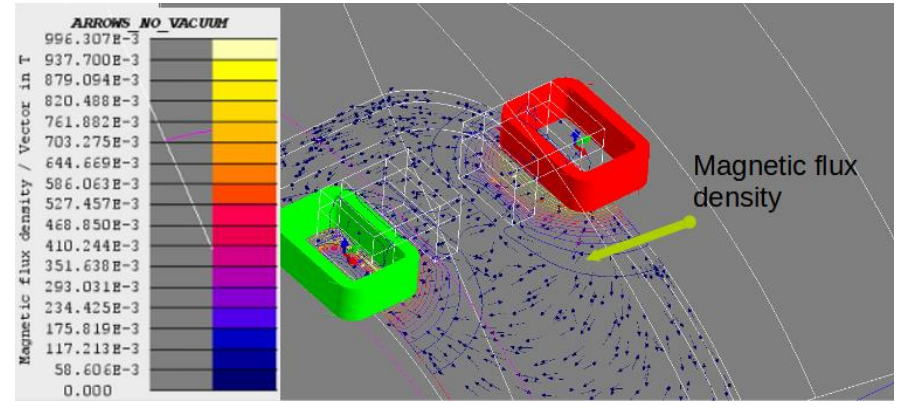

(a)

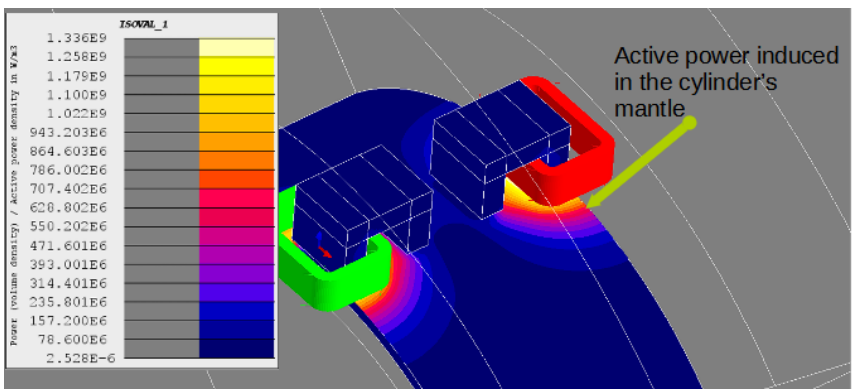

(b)

Figure 9. Distribution of magnetic induction (a) and active power (b) on the surface of the cylinder.

For the calculated active power, the temperature distribution in the cylinder area covered by the electromagnetic influence of the inductor is then determined, taking into account the nonlinear relationship of thermal conductivity $\lambda$ and temperature T. This feedback is represented by block [2] in Figure 8. Due to the fact that, in the modeled process, the surface temperature of the cylinder does not exceed the Curie temperature $\mathrm{T}_{\text {cur }}$, it is possible, without making a significant error, to uncouple the electromagnetic and temperature fields, so that after calculating the temperature distribution $\mathrm{T}$ there is no need to recalculate the active power $\mathrm{p}_{\mathrm{v}}$ in a given calculation step. This significantly accelerates the calculations. After calculating the temperature distribution on the surface of the cylinder, the transition to the next calculated time interval takes place $t=t+\Delta t$, i.e., the cylinder is moved by an angle $\alpha=\alpha+10^{\circ}$. Taking into account the thermal history from the previous interval step, the redistribution of the active power on the surface of the cylinder 
is calculated again. Of course, the value of the time step $\Delta t$ depends on the modeled rotational speed of the cylinder. The presented calculation cycle is performed until the rotating cylinder reaches a quasi-steady thermal state. An example of the temperature field distribution on the surface of the rotating cylinder is shown in Figure 10a. Figure 10b shows temperature oscillations along the circumference of the cylinder in a thermally steady state.

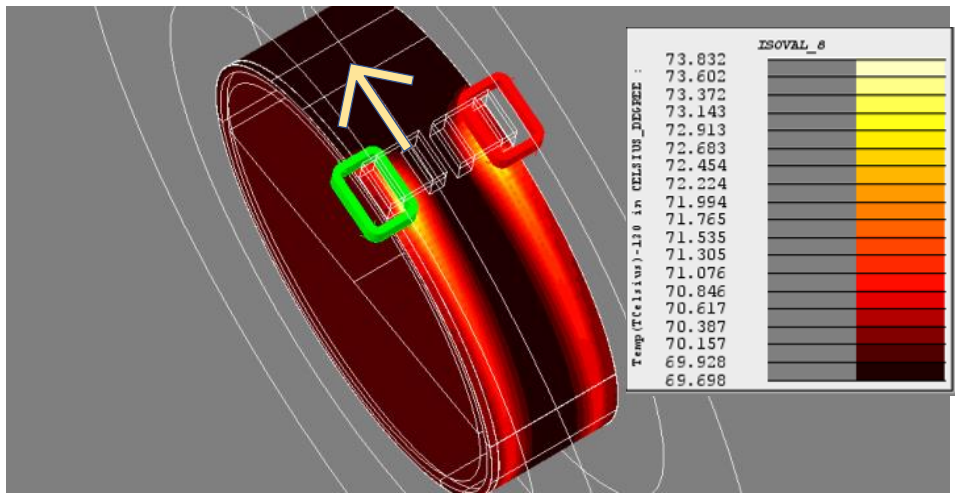

(a)

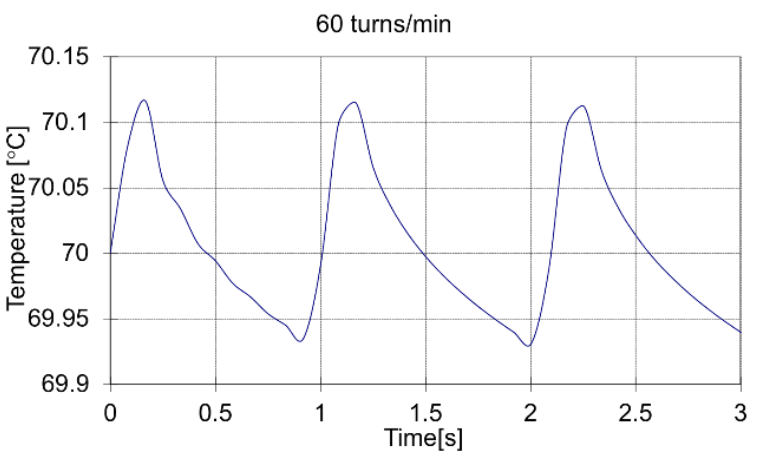

(b)

Figure 10. Results of thermal calculations for several cylinder shifts (a); temperature fluctuations under the inductor for three turns of the cylinder with a rotational speed of one turn per second (b).

Based on the calculations, it can be concluded that in a quasi-steady thermal state the temperature fluctuations on the surface of the cylinder along its circumference caused by its rotation are negligible $\left(\Delta \mathrm{T} \leq 0.2^{\circ} \mathrm{C}\right)$. Thus, in the analyzed setup, using a stationary inductor for cylinder heating enables an almost constant temperature profile to be obtained along the cylinder circumference, thanks to its rotational movement. As a consequence, the two-dimensional model is sufficient to determine the dynamic properties of the heated rotating cylinder. This enables the calculations to be accelerated significantly. The model shown in Figure 11 was used to determine the temperature distribution along the cylinder generatrix under different operating conditions. It was also used to study various algorithms, ensuring a given temperature distribution along the cylinder axis. The results will be presented in Section 4 .

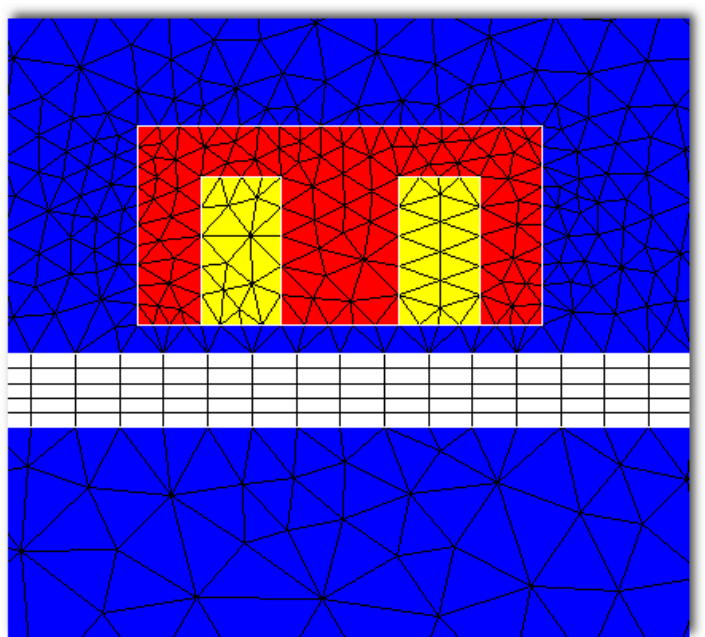

(a)

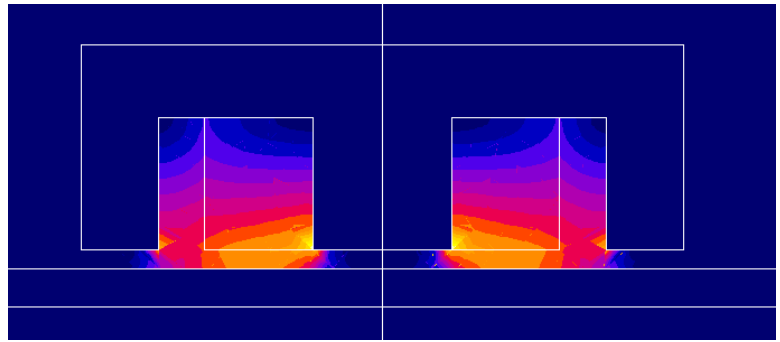

(b)

Figure 11. Division of the 2D system into finite elements (a); magnetic induction distribution in the inductor-cylinder system (b). 


\section{Temperature Profile Control}

As discussed in previous sections, the analyzed drying method relies on a contact heat exchange between the cylinder and the tape. This implies a direct relationship between the dryness of the material and the drying temperature. Consequently, in order to be able to shape the dryness profile of cotton tape, it is necessary to facilitate the shaping of a transverse surface temperature profile along the cylinder generatrix. Taking into account the characteristics of heat exchange in the induction heated rotating cylinder (as analyzed in Section 2), a set of stationary inductors can be used to heat the cylinder surface. Figure 12 shows an example of a transverse profile of the surface temperature of a cylinder heated by six stationary inductors powered by a temperature controller with a set temperature value of $80^{\circ} \mathrm{C}$ in a steady thermal state. Although the temperature profile can be shaped to some extent, there is significant irregularity in the temperature distribution.

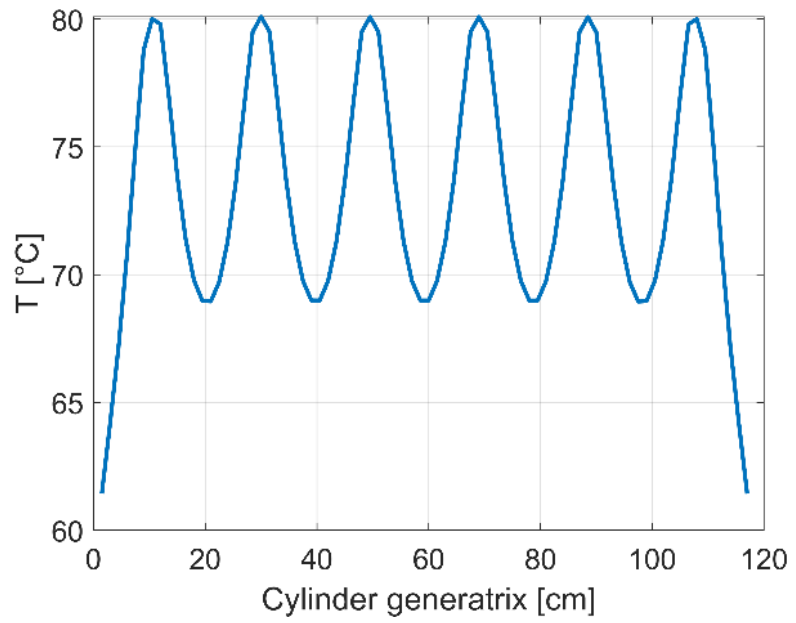

Figure 12. Temperature profile in the heat-steady state during temperature control with six inductors.

Obviously, the larger the number of stationary inducting units, the higher the uniformity of the temperature distribution at the cylinder surface. However, a larger number of dedicated power sources (HF generators) are also required, which is quite an expensive solution. Alternatively, a significant improvement in the uniformity of the temperature profile and much more flexible shaping can be achieved by the use of a movable inductor. This approach enables the generation of the required amount of thermal energy in any area of the cylinder, so that even highly demanding requirements can be fulfilled. As the heating and drying system becomes a two-degrees-of-freedom system, a two-loop control system is required. One of the loops controls the heating power, while the other controls the position of the inductors. A diagram of the system is shown in Figure 13.

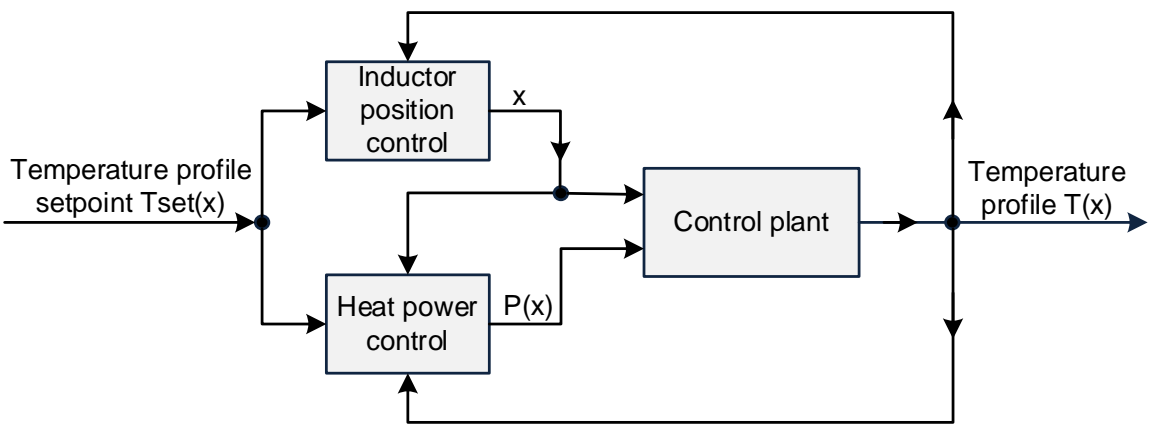

Figure 13. Block diagram of a two-circuit temperature control system, where $\mathrm{x}$-position along the forming cylinder, Tset $(x)$ —-temperature profile setpoint, $\mathrm{T}(\mathrm{x})$-temperature profile, $\mathrm{P}(\mathrm{x})$ —heat power profile. 
The characteristics and final performance of the system are determined by appropriate applied algorithms for both temperature and position control. For heating power control, a simple on-off algorithm can be used, or, after determining the dynamic properties of the object, a PID-type controller. A more specific solution is necessary when it comes to position control. The most straightforward method is to enable a systematic, cycling movement of the inductor along the cylinder generatrix. A flowchart of such an algorithm is shown in Figure 14.

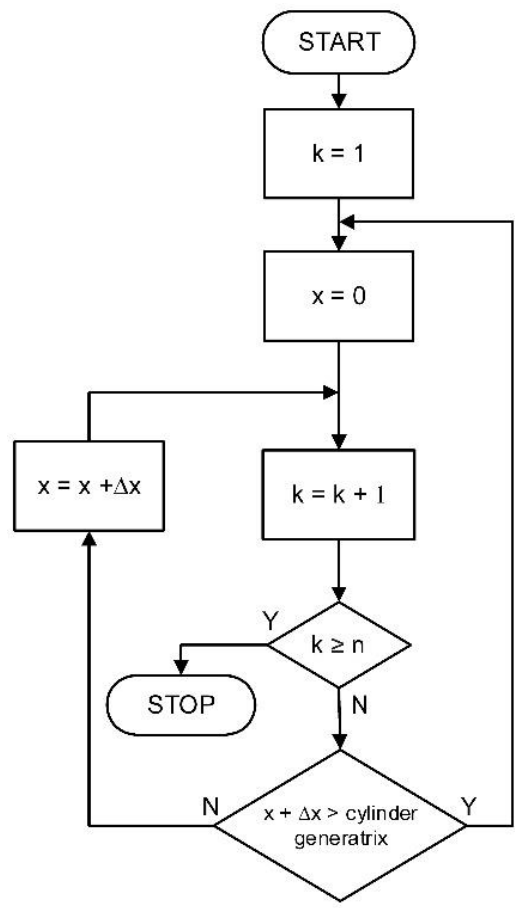

Figure 14. Flowchart of a systematic algorithm for inductor movement, where $\mathrm{x}$ is a coordinate along the cylinder generatrix, $\mathrm{k}$ is an experiment step, $\mathrm{P}$ is heat power, and $\mathrm{n}$ is the maximum of experimental steps.

The systematic algorithm addresses the most elementary demands resulting from the tape drying process. By enabling the highly uniform spread of thermal energy over the cylinder surface, the algorithm reduces variations in the temperature profile, which is crucial for proper drying of the tape. However, since this algorithm does not take into account the whole current transverse distribution of the temperature of the cylinder, the system is unable to compensate for heat energy losses in the areas with higher humidity. A flowchart of an algorithm that takes into account information on the temperature profile of the cylinder surface is shown in Figure 15.

The main idea behind this algorithm is to direct the inductor to the position, $\mathrm{i}$, where there is the greatest demand for heating power at a given moment. Based on a discrete form of the temperature profile $\mathrm{T}(\mathrm{i})$, the corresponding set of heating power values $\mathrm{P}(\mathrm{i})$ is calculated according to a PD control strategy, and finally the coordinate, $i$, of the largest element in vector $\mathrm{P}(\mathrm{i})$ is determined. This is the position where the inductor is located for a given time step, when heating power is generated in the cylinder mantle.

To compare the algorithms, simulation studies were performed using the numerical model presented in Section 3. Two variants of the inductor power supply were taken into account: constant power and adjustable power. In the first variant, after setting the inductor in a designated position, it was supplied with a constant heating power. In the second variant, the heating power depended on the temperature error at the designated position of the inductor.

To compare the results, a synthetic quality index was defined. This index expresses the unevenness of the temperature distribution that occurs throughout the heating process, 
in the form of the average value of the standard deviation of the temperature for each calculation step, expressed by the relationship

$$
I=\frac{1}{n} \sum_{k=1}^{n} \sqrt{\frac{1}{m-1} \sum_{i=1}^{m}\left(T_{k}(i)-\frac{1}{m} \sum_{j=1}^{m} T_{k}(j)\right)}
$$

where $\mathrm{T}$-temperature; $\mathrm{K}$-simulation step number; $\mathrm{N}$-number of simulation steps; $\mathrm{i}$, $\mathrm{j}-$ inductor position number; and $\mathrm{M}-$ maximum number of inductor positions.

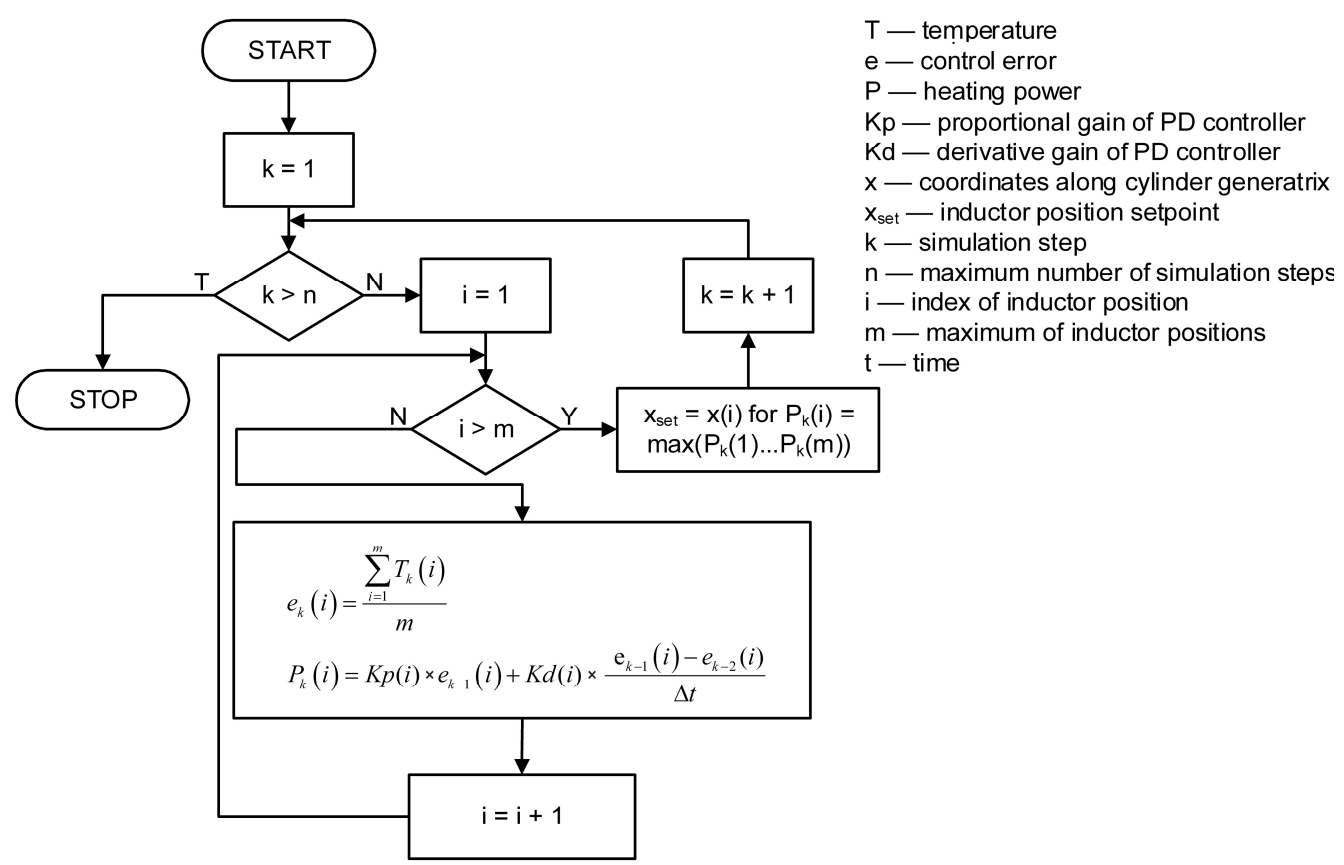

Figure 15. Inductor movement algorithm based on the temperature profile of the cylinder surface.

The values of the simulated quality index I are shown in Figure 16.

As can be seen in Figure 16, the temperature profile-sensitive algorithm shows a clear advantage over the systematic algorithm due to the high uniformity of the obtained temperature distribution, which should also allow flexible temperature profiles and the related dryness profiles to be obtained.

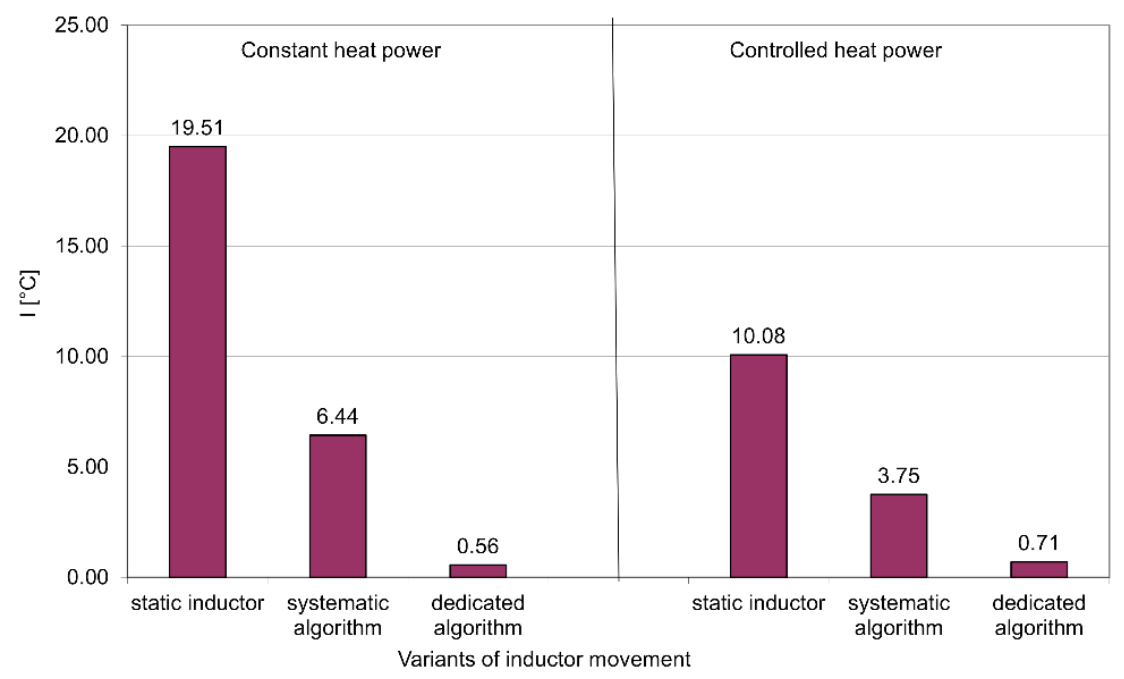

Figure 16. Values of indicator I calculated for different variants of inductor displacement and power supply. 
Having a single inductor might be a quite significant limitation for industrial drying systems where large drying cylinders are normally used. In such cases, directing heat energy at only a single spot on the cylinder surface at a given moment may be insufficient to achieve the required temperature profile. Moreover, replacing a systematic algorithm with an algorithm taking into account the current temperature profile of the cylinder surface results in a significant degradation of the uniformity of the profile. This problem can be solved and the flexibility of the whole system can be increased significantly by using a set of independent inductors, located in such a way that the maximal area of the cylinder can be covered. An example of such an approach was developed, in which two groups of three inductors are used with a dedicated positioning algorithm (Figure 17a).

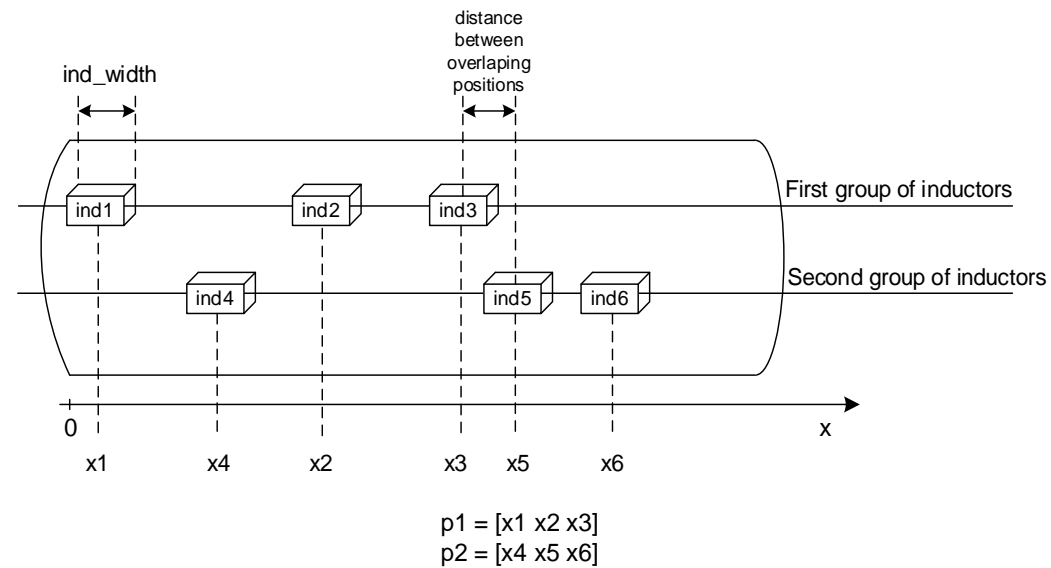

(a)

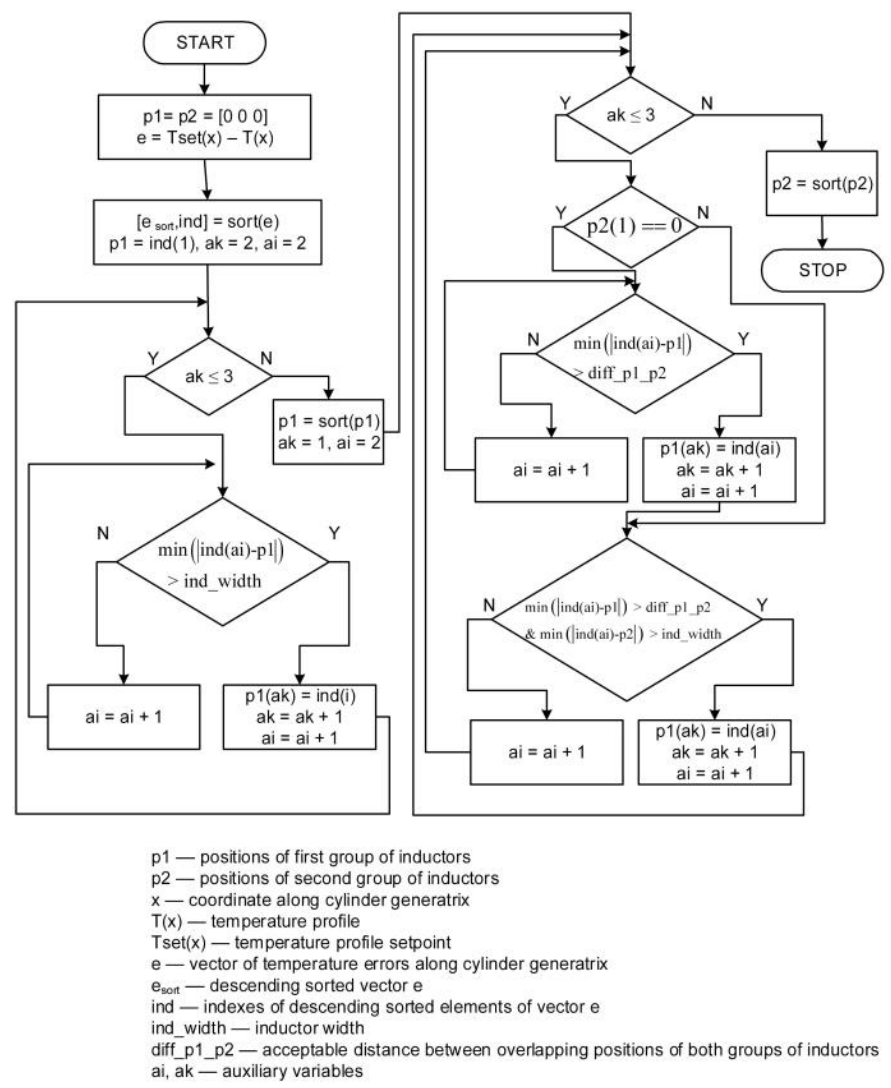

(b)

Figure 17. Scheme of the organization of inductors in a $2 \times 3$ arrangement (a) and a network of actions by the algorithm for determining the positions of the inductors along the cylinder generatrix, based on the temperature profile $(\mathbf{b})$. 
The flowchart of the algorithm is shown in Figure $17 \mathrm{~b}$. After simple modification, it can be used for systems counting any number of inductors divided into any number of groups.

The algorithm in Figure 17 controls the locations of the inductors, which are arranged in two groups of three inductors. The inductors are moved to places characterized by the highest temperature error, taking into account limitations including the width of the inductor (the distance between inductors in the same group must be greater than their width) and the width of the overlapping interactions of inductors in different groups.

To compare the proposed algorithm to the systematic approach applied for a given set of inductors a heating experiment to the required temperature of $70{ }^{\circ} \mathrm{C}$ was conducted. The experiment illustrated the control quality in different heating phases. The process requirements were to heat up the cylinder surface uniformly from the ambient temperature and stabilize it at the required level, maintaining uniform temperature distribution along the cylinder generatrix. During the experiment, the irregularity indicators of the temperature profiles along the cylinder generatrix were determined based on the maximum and minimum values of the profile: $\Delta \mathrm{T}(\mathrm{t})=\mathrm{T}_{\max }(\mathrm{t})-\mathrm{T}_{\min }(\mathrm{t})$. The results are shown in Figure 18.

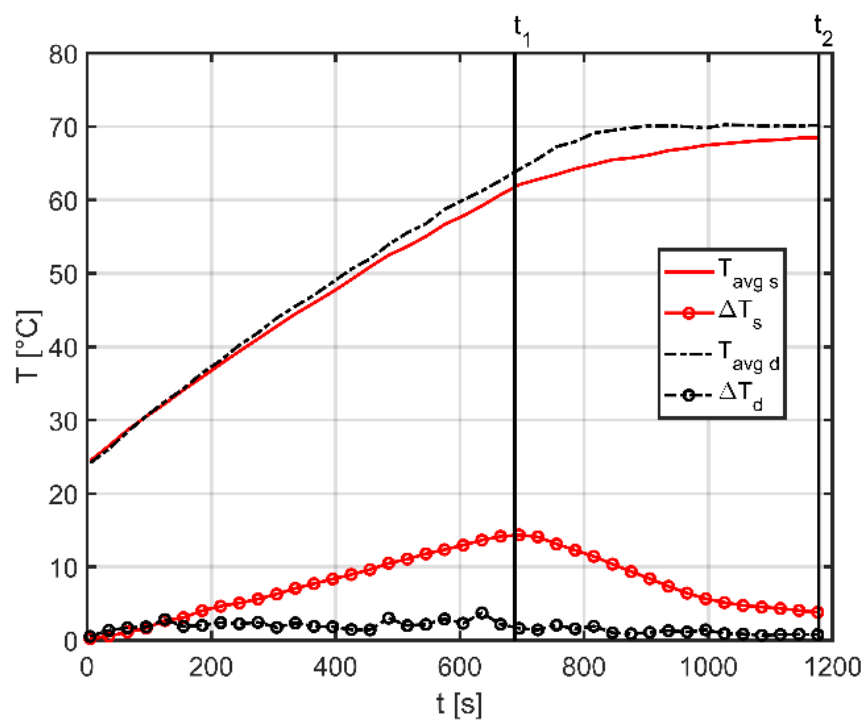

Figure 18. Temperature waveforms of the cylinder surface during heating (averaged values along the perimeter of the cylinder, $\mathrm{T}_{\mathrm{avg}}$, and the irregularity indicators of the temperature profiles along the cylinder generatrix; $\mathrm{s}$ - systematic algorithm; $\mathrm{d}$-dedicated algorithm).

Analyzing the irregularity indicators of the temperature profiles along the cylinder generatrix shown in the lower part of Figure 18, it can be seen that, during the whole experiment, the difference between the maximum and minimum temperatures on the drying cylinder surface did not exceed $3{ }^{\circ} \mathrm{C}$, whereas with the systematic algorithm it reached $14^{\circ} \mathrm{C}$. This proves that much higher uniformity of temperature distribution was achieved using the dedicated algorithm. Moreover, the unevenness of the temperature distribution during the experiment remained at a fairly constant level with the dedicated algorithm, whereas with the systematic algorithm it exhibited a clear maximum at $t_{1}$. More detailed analysis of the experiment, especially of the temperature distributions along the forming cylinder shown in Figure 19, revealed that because the boundaries of the cylinder naturally have much higher heat losses than the center, even when supplied with the full available power the systematically positioned inductors are unable to deliver enough heating energy. This results in a high irregularity of the temperature profile for the systematic algorithm, especially in the heating-up phase of the process, where it reached $14{ }^{\circ} \mathrm{C}$ at time $\mathrm{t}_{1}$ (Figure 19a). At $\mathrm{t}_{1}$, the internal part of the cylinder surface reached the set temperature value, so it ceased to be heated. After $t_{1}$, only the points that had not yet 
reached the set temperature value were heated. As a result, the temperature difference between the sides of the cylinder and its center began to decrease and reached around $3{ }^{\circ} \mathrm{C}$ at the end of the experiment (Figure 19b). Figure 19 shows that the course of the experiment was qualitatively different when the dedicated positioning algorithm was used. The dedicated algorithm ensured uniform heating of the whole cylinder surface from the very beginning of the process so that the irregularity indicators of the temperature profiles along the cylinder generatrix did not exceed $3{ }^{\circ} \mathrm{C}$ during the whole experiment. At the same time, the dynamics of the whole process were maintained as the averaged temperature at the cylinder surface reached its set-point value slightly faster than for the systematic algorithm, which can be seen in the upper part of Figure 18.

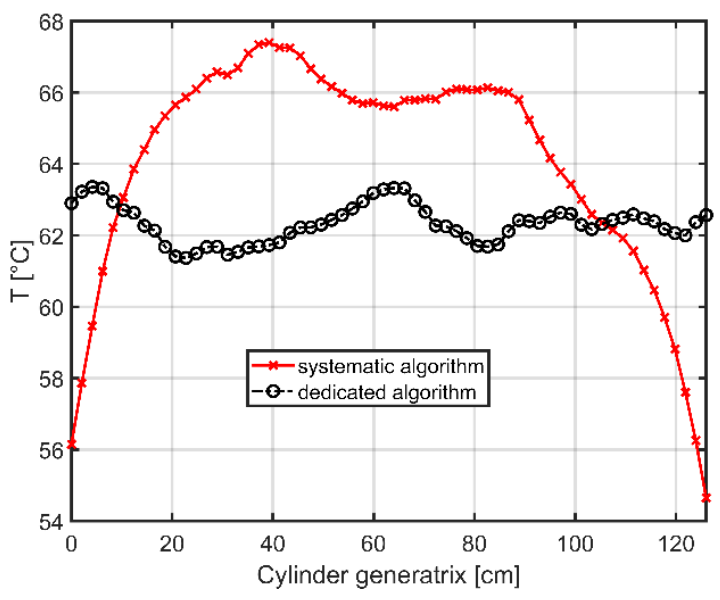

(a)

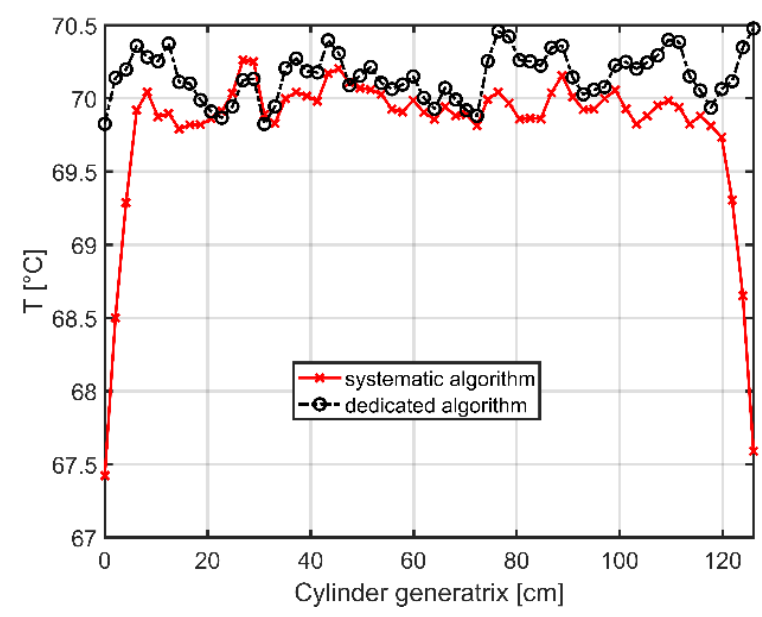

(b)

Figure 19. Temperature distribution along the forming cylinder obtained at time $t_{1}(\mathbf{a})$ and at the end of the experiment $(\mathbf{b})$.

Finally, to illustrate the broad functionalities and flexibility of the developed temperature control system, a two-stage experiment was performed. The results are shown in Figures 20 and 21. The experiment started with a $20 \mathrm{~min}$. heating phase from ambient temperature to the required temperature of $50{ }^{\circ} \mathrm{C}$, during which a uniform temperature profile along the cylinder generatrix was assumed. Then, the temperature profile was commanded to be changed as quickly as possible to a linear function in the range of $45-55^{\circ} \mathrm{C}$. The space temperature distribution over time shown in Figure 20 proves that both goals were successfully achieved. The detailed diagrams of temperature distributions at the end of each phase indicate that the required temperature profiles were fulfilled with high accuracy 
of $\pm 0.2{ }^{\circ} \mathrm{C}$ for the uniform distribution and $\pm 0.5{ }^{\circ} \mathrm{C}$ for a linear distribution. These features enable the possibility of obtaining a dried cotton tape with any desired dryness profile.

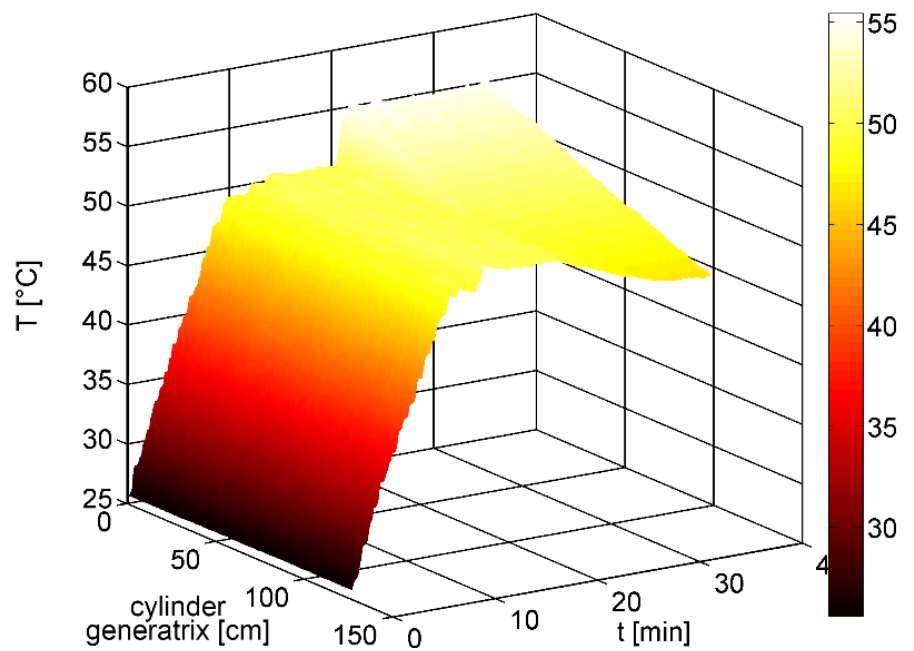

Figure 20. Temperature distribution along the forming cylinder over time.

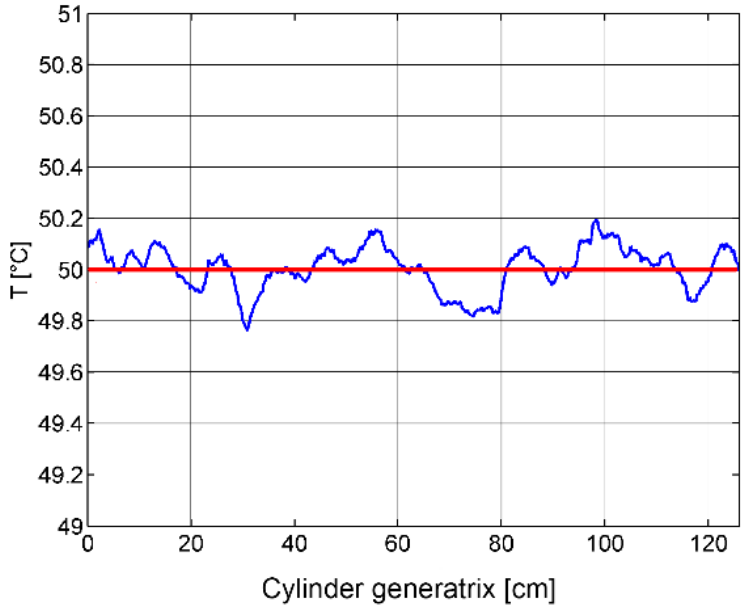

(a)

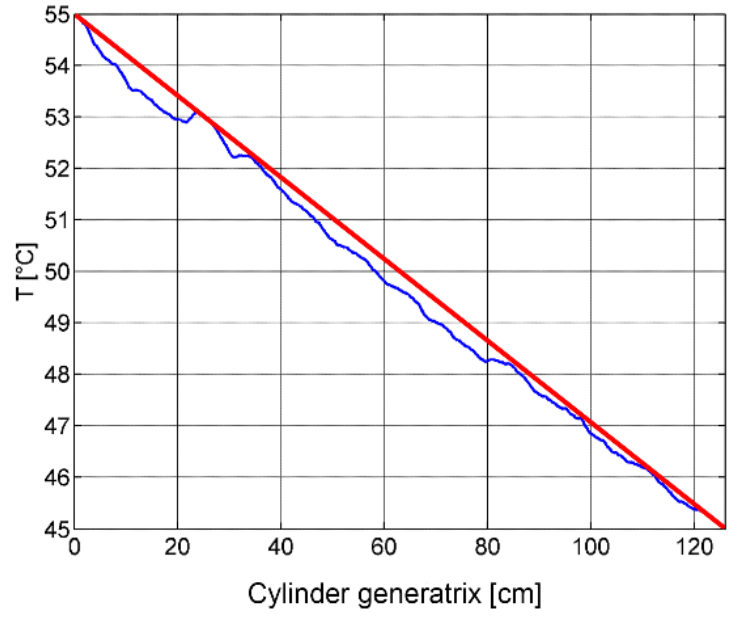

(b)

Figure 21. Transverse temperature profile of the surface of the cylinder after the first (a) and second (b) stages of the experiment (setpoint-red, measured value-blue).

\section{Dryness Control}

The overall aim of this study was to develop a solution for the dryness control of a wet cotton tape. We used an induction heated cylinder, the temperature of which can be measured and controlled. The output signal of the entire system was the absolute humidity of the tape, measured using a microwave moisture meter and defined as [31]:

$$
\mathrm{M}=\frac{\mathrm{m}_{\mathrm{w}}}{\mathrm{m}_{\mathrm{m}}+\mathrm{m}_{\mathrm{w}}} \times 100 \%
$$

where $m_{w}$ is the mass of water and $m_{m}$ is the mass of cotton.

Since the dryness of cotton tape is more often used in practice, it can be defined as:

$$
\mathrm{D}=100 \%-\mathrm{M}
$$

where $\mathrm{D}$ is cotton dryness.

From the point of view of control theory, the controlled plant can be regarded as a block with heating power $\mathrm{P}$ at the input and the dryness of the material $\mathrm{D}$ as the output, as shown in Figure 22a. An additional available intermediate signal is the surface temperature 
of the cylinder, which can serve as an auxiliary source of information for the control system, as illustrated in Figure 22b. Therefore, different types of control system structures can be applied and analyzed, including a classic PID-type controller within a single control loop stretched between the material dryness signal and the heating power signal (variant a), and a cascade controller, the operation of which is influenced by auxiliary surface temperature signal (variant b).

(a)

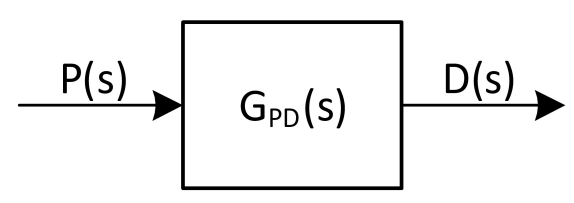

(b)

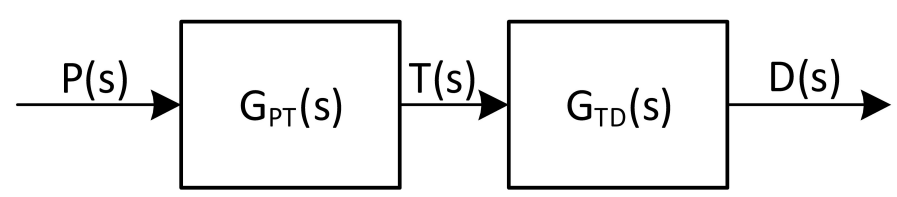

Figure 22. Models of the object developed for the needs of both analyzed variants for controlling the dryness of a cotton tape: for classic PID-type controller (a) and for cascade controller (b), where P is the heating power $(\mathrm{W}), \mathrm{D}$ is the dryness of the material tape $(\%), \mathrm{T}$ is the surface temperature of the cylinder $\left({ }^{\circ} \mathrm{C}\right), \mathrm{G}$ is the operator transmittance, and $\mathrm{t}$ is time (s).

To estimate the transfer function parameters of the models in Figure 22, an experimental identification procedure was performed. A $1000 \mathrm{~W}$ step input response of the whole system (i.e., from the heating power to the dryness of the tape) was recorded, along with the surface temperature change during the experiment. The system identification tool from the System Identification Toolbox Package Matlab R2021a was used to determine the optimal parameters of the models from Figure 22. It showed that satisfactory modelling quality was achieved using first-order inertia blocks, expressed by Equation (13) [38] for each component of the model-i.e., $\mathrm{G}_{\mathrm{PD}}(\mathrm{s}), \mathrm{G}_{\mathrm{PT}}(\mathrm{s}), \mathrm{G}_{\mathrm{TD}}(\mathrm{s})$.

$$
\mathrm{G}(\mathrm{s})=\frac{\mathrm{K}}{\mathrm{s} \times \mathrm{N}+1}
$$

where $\mathrm{K}$ is the gain and $\mathrm{N}$ is the time constant.

The optimal parameters for the models from Figure 22 determined by the identification procedure are gathered in Table 2.

Table 2. Parameters of the transfer function models from Figure 22.

\begin{tabular}{cccc}
\hline & $\mathrm{G}_{\text {PD }}$ & $\mathrm{G}_{\mathbf{P T}}$ & $\mathrm{G}_{\text {TD }}$ \\
\hline $\mathrm{K}$ & $3.99 \times 10^{-2} \% / \mathrm{W}$ & $1.48 \times 10^{-2} \mathrm{~K} / \mathrm{W}$ & $2.61 \% / \mathrm{K}$ \\
$\mathrm{N}$ & $4.42 \times 10^{3} \mathrm{~s}$ & $2.05 \times 10^{3} \mathrm{~s}$ & $1.87 \times 10^{3} \mathrm{~s}$ \\
\hline
\end{tabular}

The final identification accuracy is shown in Figure 23, which plots the relative dryness responses of the real plant and its two transfer function models to the $1000 \mathrm{~W}$ step input heating power. 


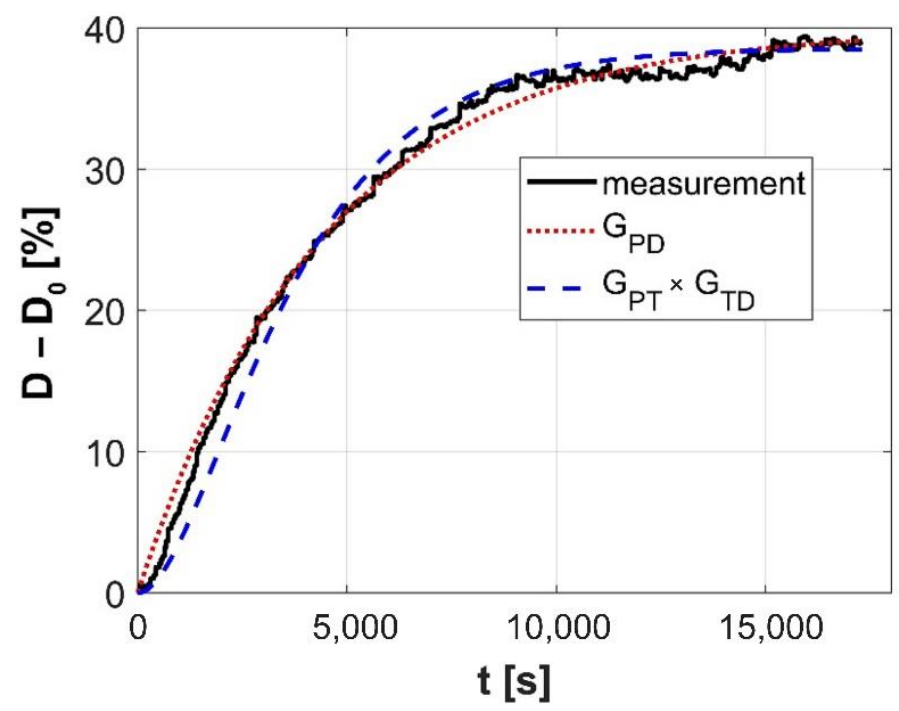

Figure 23. Responses of the object of research and two models to the jumping force with a power of $1000 \mathrm{~W}$ (D and D0 indicate the current dryness of the tape and its initial dryness at the start of the experiment, respectively).

As both models demonstrated similar modelling accuracy, only variant $b$ was used in further research, as it is suitable for simple one-loop control and opens the possibility of building a cascade control system. The two analyzed control systems are shown in Figure 24.
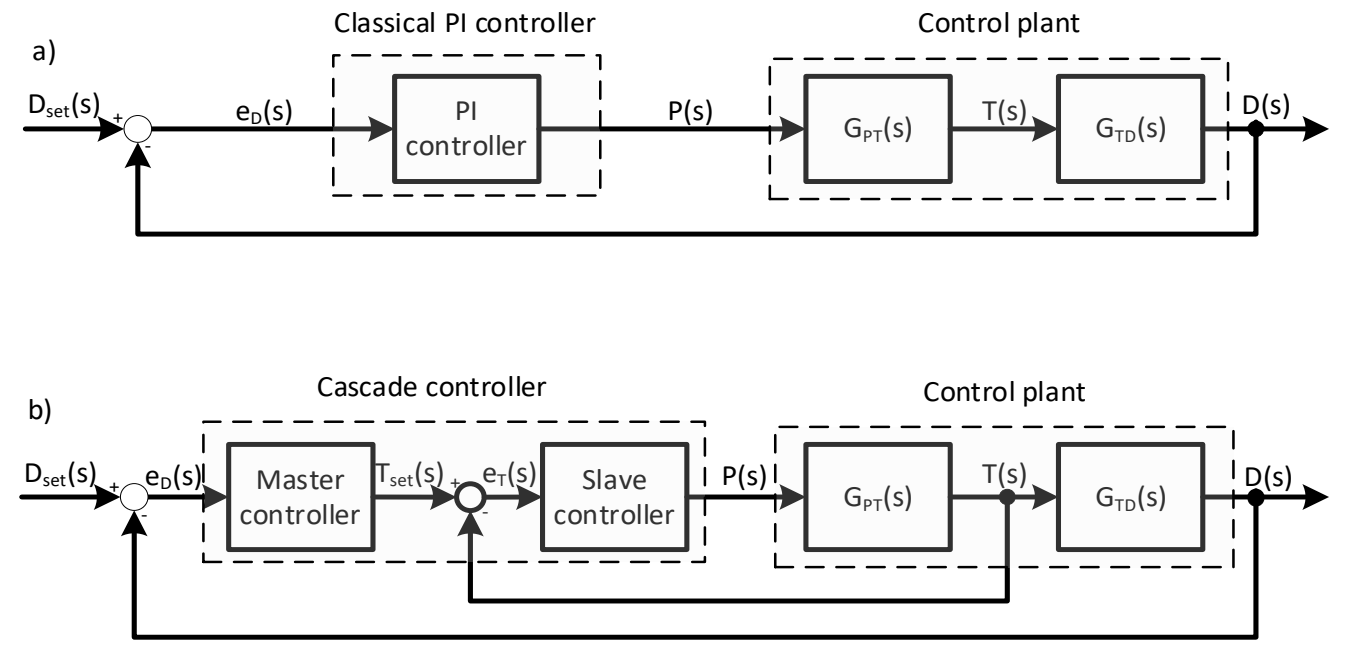

Figure 24. Analyzed systems for controlling the dryness of cotton tape, using a classic PI controller (a) and a cascade controller (b), where $\mathrm{D}_{\text {set }}$ is the dryness setpoint value, $\mathrm{e}_{\mathrm{D}}$ is the dryness control error, $\mathrm{P}$ is the heating power, $\mathrm{T}$ is the surface temperature of the cylinder, $\mathrm{D}$ is the dryness of the cotton tape, $\mathrm{T}_{\text {set }}$ is the value set for the surface temperature of the cylinder, and $\mathrm{e}_{\mathrm{T}}$ is the surface temperature control error.

In the classic control loop, the heating power value, which is the input of the plant, is determined only by the dryness of the tape. In the case of a cascade controller, the master controller is fed by the dryness signa and determines the setpoint for the slave controller-i.e., the temperature required at the cylinder surface. Thus, the heating power depends on both the dryness deviation of the tape and the temperature deviation of the cylinder surface. Moreover, the cascade approach ensures a faster reaction by the control system to changes in the humidity of the tape, which results in temperature changes at the drying cylinder. In both control structures, a PI controller with a parallel structure (14) was used: 


$$
\mathrm{G}(\mathrm{s})=\mathrm{Kp}+\mathrm{Ki} \times \frac{1}{\mathrm{~s}}
$$

where $\mathrm{Kp}$ is the proportional gain of the PI controller and $\mathrm{Ki}$ is the integral gain of the PI controller.

The control systems for both structures from Figure 23 were synthesized using the PID Tuner tool in the Simulink R2021a package by MathWorks, based on the model parameters given in Table 3. The controller settings were adjusted so that the step input response of the entire system exhibited a $5 \%$ overshoot in dryness. Table 3 presents the controller settings and Figure 25 the results of the simulated dryness control for both structures.

Table 3. Settings of the controllers from Figure 23.

\begin{tabular}{cccc}
\hline & PI Controller & Master Controller & Slave Controller \\
\hline $\mathrm{Kp}$ & $34.6(\mathrm{~W} / \%)$ & $0.75(\mathrm{~K} / \%)$ & $1064(\mathrm{~W} / \mathrm{K})$ \\
$\mathrm{Ki}$ & $0.01(\mathrm{~W} / \% / \mathrm{s})$ & $4.2 \times 10^{-4}(\mathrm{~K} / \% / \mathrm{s})$ & $2.2(\mathrm{~W} / \mathrm{K} / \mathrm{s})$ \\
\hline
\end{tabular}

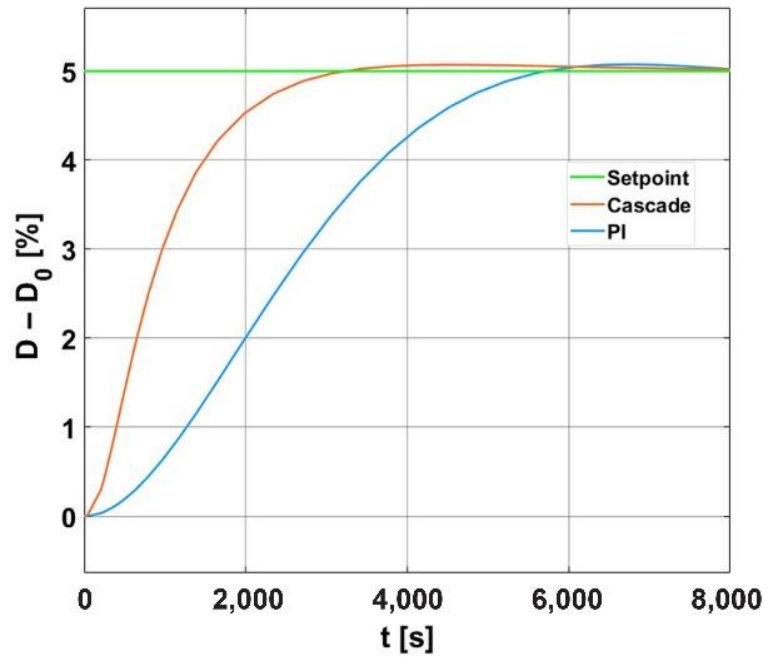

Figure 25. Simulation runs of tape dryness adjustment using both adjustment variants.

Both control systems were implemented in the experimental setup described in Section 3 and some experimental verification was performed. An example of a step input response including the waveforms of all signals of interest is shown in Figure 26.

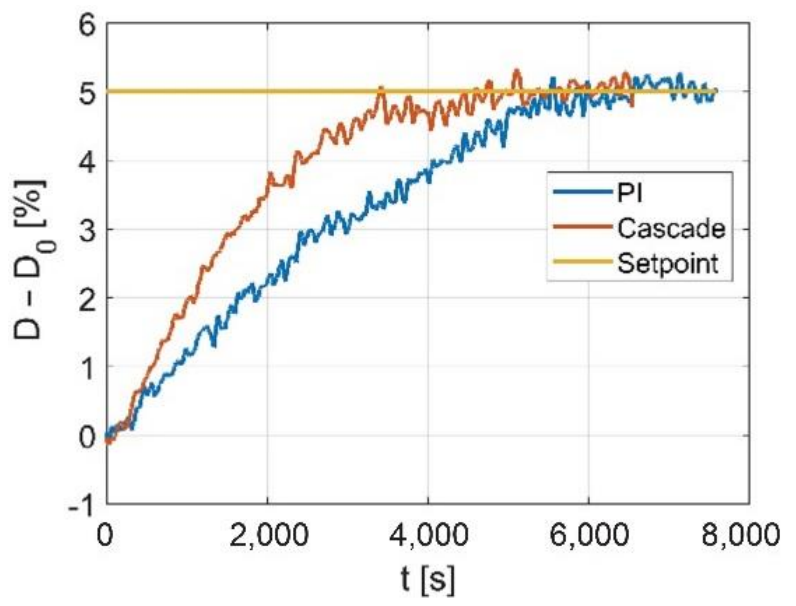

(a)

Figure 26. Cont. 


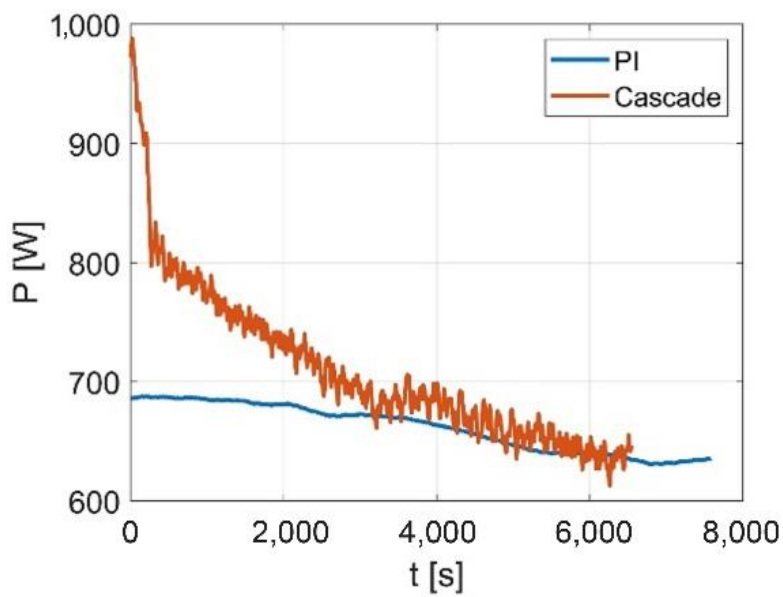

(b)

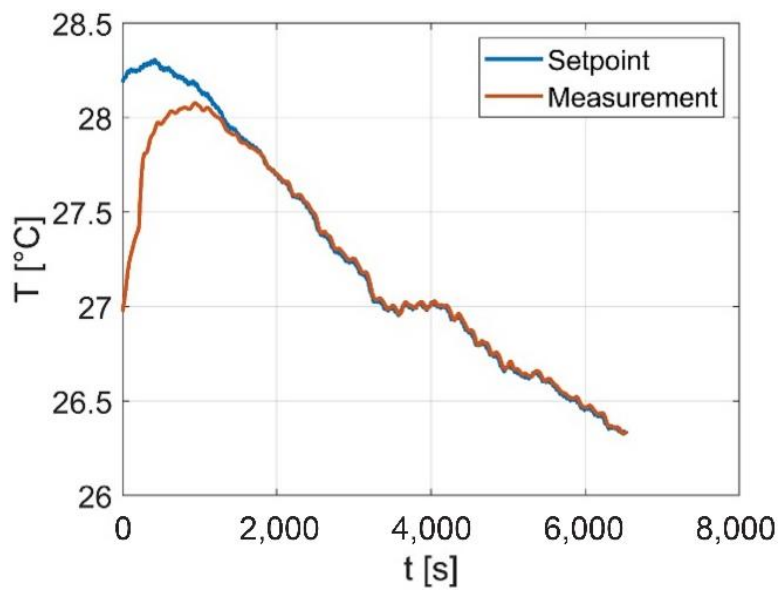

(c)

Figure 26. Experimental results of adjusting the dryness of the tape after changing the set value of dryness by $5 \%$. Dryness waveforms (a), heating power waveforms (b), and cylinder surface temperature waveforms during cascade control (c).

As can be noticed by comparing Figure 26a with Figure 25, the courses of the control action and the final control quality obtained in the experiments were very similar to the simulations for both types of control systems. This proves the correctness of the elaborated models of the control object, as well as the effectiveness of the chosen control methods.

The quality achieved in both control variants was assessed on the basis of two performance indicators: the time of reaching the zone of $10 \%$ around the set-point (marked as $\mathrm{T}_{\mathrm{S}}$ ) and the ITAE integral criterion, defined as:

$$
\operatorname{ITAE}=\sum_{\mathrm{k}=1}^{\mathrm{n}}\left|\mathrm{D}_{\text {set }}(\mathrm{k})-\mathrm{D}_{\mathrm{m}}(\mathrm{k})\right| \times \mathrm{k} \times \Delta \mathrm{t}
$$

where $\mathrm{D}_{\text {set }}$ - set value of dryness; $\mathrm{D}_{\mathrm{m}}$ —measured dryness value; $\mathrm{k}$ —adjustment step; and $\Delta \mathrm{t}$-sampling period.

The values of the control quality indicators are collected in Table 4.

Table 4. Settings of the controllers from Figure 24.

\begin{tabular}{ccc}
\hline & Ts (s) & ITAE (\% s) \\
\hline PI & 4972 & $2.24 \times 10^{7}$ \\
Cascade & 3189 & $9.74 \times 10^{6}$ \\
\hline
\end{tabular}


As anticipated, the cascade control outperformed the classical one-loop approach, ensuring a more than $30 \%$ faster response by the whole system and a significant reduction in the ITAE performance index. This was obtained by shortening the path along which information about the state of the system has to pass in the feedback loop, through the controller, to the input of the plant. Consequently, as shown in Figure 26b, the cascade controller applies much more heating power in the initial phase of the step response compared to the classic PI controller. This results in the dryness set point being reached faster. At the same time, the slave controller brings the surface temperature of the cylinder quite quickly to the setpoint value determined by the master controller. It then quite faithfully tracks the changes to the set temperature value. Since the cascade controller converts the dryness loss to the temperature of the cylinder surface, the key to controlling the dryness profile along the forming cylinder is the ability to control the temperature profile, as presented above.

\section{Conclusions}

In this paper, we proposed an alternative approach to drying tape-shaped fibrous materials. Induction heating was used in a drying system consisting of a set of cylinders through which the dried tape runs. By enabling movement of the inductors (electromagnetic field sources), the system provides a high level of flexibility in terms of reacting to the varying humidity of the dried tape. Imaging the temperature field on the surface of the drying cylinder provided a supplementary source of information during the drying process, enabling a temperature profile of the control sub-system to be created. This approach constitutes an important step forward compared to classical water steam-based industrial solutions, significantly improving the energy efficiency of the process and the final quality of the product. Based on simulations using a numerical model of electromagnetic and thermal phenomena, we conducted a detailed analysis of energy generation and heat exchange in the system. It was proven that all aspects of the considered system, including the rotating movement of the cylinder, can be modelled numerically with satisfactory accuracy, giving us possibility of determining parametric models for control purposes. Two types of humidity control systems, a one-loop feedback control and a cascade control, were designed and analyzed. By introducing the temperature profile control subsystem, we ensured a more than $30 \%$ faster response of the whole dryness control system, which can improve the energy efficiency of the production process. Experimental verification of the proposed method was performed using a semi-industrial setup equipped with a computer-based control system. Our results prove that high quality dryness control can be achieved, especially using a cascade control system with the temperature profile of the drying cylinder surface as an auxiliary signal.

Author Contributions: Conceptualization, J.K., A.F. and P.U.; methodology, A.F. and P.U.; formal analysis, J.K.; validation, A.F.; software, P.U., writing-original draft preparation, A.F. and P.U.; visualization, A.F. and P.U.; writing—review and editing, J.K.; supervision, J.K. All authors have read and agreed to the published version of the manuscript.

Funding: This research received no external funding.

Institutional Review Board Statement: Not applicable.

Informed Consent Statement: Not applicable.

Data Availability Statement: Not applicable.

Conflicts of Interest: The authors declare no conflict of interest.

\section{References}

1. Chen, X.; Zheng, Q.; Dong, Y. Theoretical Estimation of Evaporation Heat in Paper Drying Process Based on Drying Curve. Processes 2021, 9, 1117. [CrossRef]

2. Pavlík, Z.; Mihulka, J.; Fiala, L.; Černý, R. Application of Time-Domain Reflectometry for Measurement of Moisture Profiles in a Drying Experiment. Int. J. Thermophys. 2012, 33, 1661-1673. [CrossRef] 
3. Slätteke, O.; Åström, K.J. Modeling of a Steam Heated Rotating Cylinder-A Grey-Box Approach. In Proceedings of the American Control Conference, Portland, OR, USA, 8-10 June 2005; pp. 1449-1454.

4. $\quad$ Ren, D.; Yao, J.; Wang, Y. Dryer Surface Temperature Control System Based on Improved Self-Adaptive Fuzzy Smith Prediction Controller; IEEE/IET Electronic Library (IEL): Piscataway, NJ, USA, 2005; pp. 1274-1279.

5. Jang, J.-Y.; Chiu, Y.-W. Numerical and experimental thermal analysis for a metallic hollow cylinder subjected to step-wise electro-magnetic induction heating. Appl. Therm. Eng. 2007, 27, 1883-1894. [CrossRef]

6. Demir, H. Experimental and numerical studies of natural convection from horizontal concreto cylinder heated with a cylindrical heat source. Int. Commun. Heat Mass Transf. 2010, 37, 422-429. [CrossRef]

7. Kranjc, M.; Zupanic, A.; Miklavcic, D.; Jarm, T. Numerical analysis and thermographic investigation of induction heating. Int. J. Heat Mass Transf. 2010, 53, 3585-3591. [CrossRef]

8. Clemens, M.; Gjonaj, E.; Pinder, P.; Weiland, T. Numerical Simulation of Coupled Transient Thermal and Electromagnetic Fields with the Finite Integration Method. IEEE Trans. Magn. 2000, 36, 1448-1452.

9. Tsai, J.R.; Özisik, M.N. Transient, combined conduction and radiation in an absorbing, emitting, and isotropically scattering solid cylinder. J. Appl. Phys. 1988, 64, 3820-3824. [CrossRef]

10. Barglik, J.; Smagór, A.; Smalcerz, A.; Desisa, D.G. Induction Heating of Gear Wheels in Consecutive Contour Hardening Process. Energies 2021, 14, 3885. [CrossRef]

11. Zgraja, J. Simplified simulation technique of rotating, induction heated, calender rolls for study of temperature field control. Open Phys. 2018, 16, 326-331. [CrossRef]

12. Rodriguez, G.; Vasseur, J.; Courtois, F. Design and Control of Drum Dryers for the Food Industry. Part 1. Set-Up of a Moisture Sensor and an Inductive Heater. J. Food Eng. 1996, 28, 271-282. [CrossRef]

13. Kochan, O.; Kochan, R.; Bojko, O.; Chyrka, M. Temperature Measurement System Based on Thermocouple with Controlled Temperature Field. In Proceedings of the IEEE International Workshop on Intelligent Data Acquisition and Advanced Computing Systems: Technology and Applications, Dortmund, Germany, 6-8 September 2007; pp. 47-50.

14. Li, F.; Ning, J.; Liang, S.Y. Analytical Modeling of the Temperature Using Uniform Moving Heat Source in Planar Induction Heating Process. Appl. Sci. 2019, 9, 1445. [CrossRef]

15. Xie, Y.; Wang, Y. 3D temperature fi eld analysis of the induction motors with brokenbar fault. Appl. Therm. Eng. 2014, 66, 25-34. [CrossRef]

16. Silver, D.; Salmon, R.; Barbieri, E.; Drakunov, S. Towards an Integrated Welding Testbed: Temperature Field Control. In Proceedings of the American Control Conference, Philadelphia, PA, USA, 24-26 June 1998; pp. 1023-1027.

17. Chy, M.I.; Boulet, B. A New Method for Estimation and Control of Temperature Profile over a Sheet in Thermoforming Process. In Proceedings of the IEEE Industry Applications Society Annual Meeting, Houston, TX, USA, 3-7 October 2010; pp. 1-8.

18. Girault, M.; Videcoq, E. Temperature regulation and tracking in a MIMO system with a mobile heat source by LQG control with a low order model. Control Eng. Pract. 2013, 21, 333-349. [CrossRef]

19. Bougriou, C.; Bessaih, R.; Le Gall, R.; Solecki, J.C. Measurement of the temperature distribution on a circular plane fin by infrared thermography technique. Appl. Therm. Eng. 2004, 24, 813-825. [CrossRef]

20. Guen, L.L.; Huchet, F.; Dumoulin, J.; Baudru, Y.; Tamagny, P. Convective heat transfer analysis in aggregates rotary drum reactor. Appl. Therm. Eng. 2013, 54, 131-139. [CrossRef]

21. Datcu, S.; Ibos, L.; Candau, Y.; Mattei, S. Improvement of building wall surface temperature measurements by infrared thermography. Infrared Phys. Technol. 2005, 46, 451-467. [CrossRef]

22. Cardone, G.; Ianiro, A.; dello Ioio, G.; Passaro, A. Temperature maps measurements on 3D surfaces with infrared thermography. Exp. Fluids 2012, 52, 375-385. [CrossRef]

23. Johnson, M.A.; Moradi, M.H. PID Control. New Identification and Design Methods; Springer: London, UK, 2005 ; pp. 52-88.

24. Wang, L. PID Control System Design and Automatic Tuning Using MATLAB/Simulink; Wiley-IEEE Press: Hoboken, NJ, USA, 2020; pp. 31-67.

25. Matamoros, M.; Carlos, J.; Álvaro, G.B.; Sánchez, J.; Mancha, E.; Marcos, A.C.; Carrasco-Amador, J.P.; Pagador, J.B. Temperature and Humidity PID Controller for a Bioprinter Atmospheric Enclosure System. Micromachines 2020, 11, 999. [CrossRef]

26. Xiong, S.; Wu, Z.; Li, W.; Li, D.; Zhang, T.; Lan, Y.; Zhang, X.; Ye, S.; Peng, S.; Han, Z.; et al. Improvement of Temperature and Humidity Control of Proton Exchange Membrane Fuel Cells. Sustainability 2021, 13, 10578. [CrossRef]

27. Kochan, O.; Sapojnyk, H.; Kochan, R. Temperature Field Control Method Based on Neural Network. In Proceedings of the 7th IEEE International Conference on Intelligent Data Acquisition and Advanced Computing Systems: Technology and Applications, Berlin, Germany, 12-14 September 2013; pp. 21-24.

28. Vasylkiv, N.; Kochan, O.; Kochan, R.; Chyrka, M. The Control System of the Profile of Temperature Field. In Proceedings of the IEEE International Workshop on Intelligent Data Acquisition and Advanced Computing Systems: Technology and Applications, Rende, Italy, 21-23 September 2009; pp. 201-206.

29. Fraczyk, A.; Kucharski, J. Surface temperature control of a rotating cylinder heated by moving inductors. Appl. Therm. Eng. 2017, 125, 767-779. [CrossRef]

30. Rodriguez, G.; Vasseur, J.; Courtois, F. Design and control of drum dryers for the food industry. Part 2. Automatic control. J. Food Eng. 1996, 30, 171-183. [CrossRef] 
31. Bai, X.; Zhang, H.; Wang, G. Modeling of the Moving Induction Heating Used as Secondary Heat Source in Weld-Based Additive Manufacturing; Springer: London, UK, 2014; pp. 717-727.

32. Perez, S.; Thkrien, N.; Broadbent, A.D. Modelling the Continuous Drying of a Thin Sheet of Fibres on a Cylinder Heated by Electric Induction. Can. J. Chem. Eng. 2001, 79, 977-989. [CrossRef]

33. Jianliang, S.; Shuo, L.; Chouwu, Q.; Yan, P. Numerical and experimental investigation of induction heating process of heavy cylinder. Appl. Therm. Eng. 2018, 134, 341-352.

34. Shokouhmand, H.; Ghaffari, S. Thermal analysis of moving induction heating of a hollow cylinder with subsequent spray cooling: Effect of velocity, initial position of coil, and geometry. Appl. Math. Model. 2012, 36, 4304-4323. [CrossRef]

35. Bermúdez, A.; Gómez, D.; Muñiz, M.C.; Salgado, P.; Vázquez, R. Numerical simulation of a thermo-electromagneto-hydrodynamic problem in an induction heating furnace. Appl. Numer. Math. 2009, 59, 2082-2104. [CrossRef]

36. Rudnev, V. Unique Computer Modeling Approaches for Simulation of Induction Heating and Heat-Treating Processes. J. Mater. Eng. Perform. 2013, 22, 1899-1906. [CrossRef]

37. Meyer, W.; Schilz, W.M. Feasibility Study of Density-Independent Moisture Measurement with Microwaves. IEEE Trans. Microw. Theory Tech. 1981, 29, 732-739. [CrossRef]

38. Mikleš, J.; Fikar, M. Process Modelling, Identification, and Control; Springer: Berlin/Heidelberg, Germany, 2007; pp. 221-259. 